\title{
SuperDARN studies of the ionospheric convection response to a northward turning of the interplanetary magnetic field
}

\author{
J. R. Taylor ${ }^{1}$, S. W. H. Cowley ${ }^{1}$, T. K. Yeoman ${ }^{1}$, M. Lester ${ }^{1}$, T. B. Jones ${ }^{1}$, R. A. Greenwald ${ }^{2}$, G. Sofko ${ }^{3}$, J.-P. Villain ${ }^{4}$, \\ R. P. Lepping ${ }^{5}$, M. R. Hairston ${ }^{6}$ \\ ${ }^{1}$ Department of Physics and Astronomy, University of Leicester, University Road, Leicester LE1 7RH, UK \\ 2 Applied Physics Laboratory, The Johns Hopkins University, Johns Hopkins Road, Laurel, Maryland 20723-6099, USA \\ 3 Institute for Space and Atmospheric Studies, University of Saskatchewan, Saskatoon, Saskatchewan S7N 0W0, Canada \\ ${ }_{5}^{4}$ CNRS/LPCE, 3A Avenue de la Recherche Scientifique, 45701 Orléans Cedex 2, France \\ ${ }_{6}^{5}$ NASA Goddard Space Fight Center, Greenbelt, Maryland 20771, USA \\ ${ }^{6}$ W.B. Hansen Center for Space Sciences, University of Texas at Dallas, PO Box 830688, Richardson, Texas 75083, USA
}

Received: 9 December 1996 / Revised: 9 January 1998 / Accepted: 16 January 1998

\begin{abstract}
The response of the dayside ionospheric flow to a sharp change in the direction of the interplanetary magnetic field (IMF) measured by the WIND spacecraft from negative $B_{z}$ and positive $B_{y}$, to positive $B_{z}$ and small $B_{y}$, has been studied using SuperDARN radar, DMSP satellite, and ground magnetometer data. In response to the IMF change, the flow underwent a transition from a distorted twin-cell flow involving antisunward flow over the polar cap, to a multi-cell flow involving a region of sunward flow at high latitudes near noon. The radar data have been studied at the highest time resolution available $(\sim 2 \mathrm{~min})$ to determine how this transition took place. It is found that the dayside flow responded promptly to the change in the IMF, with changes in radar and magnetic data starting within a few minutes of the estimated time at which the effects could first have reached the dayside ionosphere. The data also indicate that sunward flows appeared promptly at the start of the flow change (within $\sim 2$ min), localised initially in a small region near noon at the equatorward edge of the radar backscatter band. Subsequently the region occupied by these flows expanded rapidly east-west and poleward, over intervals of $\sim 7$ and $\sim 14$ min respectively, to cover a region at least $2 \mathrm{~h}$ wide in local time and $5^{\circ}$ in latitude, before rapid evolution ceased in the noon sector. In the lower latitude dusk sector the evolution extended for a further $\sim 6 \mathrm{~min}$ before quasi-steady conditions again prevailed within the field-of-view. Overall, these observations are shown to be in close conformity with expectations based on prior theoretical discussion, except for the very prompt appearance of sunward flows after the onset of the flow change.
\end{abstract}

Key words. Ionosphere (Auroral ionosphere) · Magnetospheric physics (Magnetopause, cusp, and boundary layers; Magnetosphere-ionosphere interaction)

\section{Introduction}

Previous investigations of the flow in the high-latitude ionosphere have demonstrated that a key controlling parameter is the direction and strength of the interplanetary magnetic field (IMF). For example, the flows measured by low-altitude spacecraft which were studied by Burch et al. (1985) and Reiff and Burch (1985) have shown that when the IMF points south a twin-vortex flow pattern is present, with antisunward flow over the polar cap and return sunward flow at lower latitudes in the auroral zones. These flows are believed to be generated principally by reconnection processes at the dayside magnetopause and in the tail, which respectively open and close terrestrial flux to the interplanetary medium. The theory of these flows was first discussed by Dungey (1961), and subsequently developed e.g. by Siscoe and Huang (1985) and Cowley and Lockwood (1992). For northward IMF the flow pattern is observed to become multi-celled, with a region of sunward flow in the dayside polar cap. While the low-latitude flow cells which are located (at least partly) on closed flux tubes may continue to be driven by tail processes and nonreconnection "viscous" coupling at the magnetopause, the cells located within the polar cap are believed to be generated by high-latitude reconnection between the IMF and open tail lobe flux. Dungey (1963) first proposed that such reconnection may occur essentially simultaneously at both lobes, leading to the closure of open flux on the dayside, but Russell (1972) argued that 
a given northward-directed interplanetary field line is more likely to reconnect with one tail lobe only, particularly if a significant IMF $B_{y}$ component is present as well. In this case the amount of open flux remains unchanged by this process, but the open flux is "stirred" into circulatory motion within the polar cap. Both the large-scale twin-vortex flow pattern for southward IMF and the reversed "stirring" flow pattern for northward IMF also display asymmetries whose sense depends on the sign of IMF $B_{y}$, and which reverse between the Northern and Southern Hemispheres. These asymmetries are produced by east-west field tension effects on open flux tubes when $B_{y}$ fields are present in the interplanetary medium (Jørgensen et al., 1972; Cowley, 1981; Cowley et al., 1991).

Such IMF-dependent "steady-state" pictures of the flow, while describing much essential physics, are nevertheless deficient in a number of respects. In particular they do not address the question of how and on what time scale the flow reconfigures in response to changes in the direction of the IMF. This issue can be investigated most readily by use of ground-based radars, but both good temporal resolution (minutes), and large spatial coverage (significant fractions of the polar ionosphere) are required. Previous investigations have achieved sufficient temporal resolution, but have usually been of limited spatial coverage. Such studies have nevertheless demonstrated that the high-latitude flow near noon shows rapid initial responses (few minutes) to changes in the IMF, with subsequent evolution of the large-scale flow pattern taking place on time scales of a few tens of minutes (Etemadi et al., 1988; Todd et al., 1988; Freeman et al., 1990; Greenwald et al., 1990; Lester et al., 1993; Taylor et al., 1994; Hairston and Heelis, 1995).

Recently, however, the development of the SuperDARN coherent-scatter HF radar network has started to allow the investigation of polar ionospheric flows with good temporal resolution over much larger spatial regions (e.g. Greenwald et al., 1995a,b). In this study we discuss observations of a flow reconfiguration which followed a switch in the direction of the IMF from south to north, using observations from five SuperDARN radars, supplemented by DMSP overpass data and ground magnetic measurements. We show that a reconfiguration of the flow took place which involved the prompt appearance of a patch of sunward flow near noon (within $\sim 2 \mathrm{~min}$ ), which expanded azimuthally and polewards over intervals of $\sim 7$ and $\sim 14$ min respectively. Flow evolution in the dusk sector continued for a further $\sim 6 \mathrm{~min}$, until a quasi-steady flow pattern was reestablished within the radar field-of-view after $\sim 20$ minutes. In the following sections we describe in turn the ground-based instrumentation, the interplanetary measurements, expectations based on prior theoretical discussions, followed by a discussion of the radar observations in the interval 10-12 UT on 23 March 1995.

\section{Ground-based instrumentation}

The fields-of-view (f-o-v) of the five Northern Hemisphere SuperDARN HF radars and supporting ground magnetometer stations employed in this study are shown in Fig. 1. The map is plotted in the altitude-adjusted corrected geomagnetic coordinate system (AACGM), formerly PACE magnetic coordinates (Baker and Wing, 1990), looking down on the geomagnetic north pole at 1100 UT, the centre time of the interval under study. The combined radar coverage is about half of the northern polar hemisphere at magnetic latitudes above $70^{\circ} \mathrm{N}$, with a potential for bistatic measurements covering a third of the polar cap. Starting at $\sim 1400$ MLT and moving clockwise, the network consists of the following radars: CUTLASS-Finland $\left(62.3^{\circ} \mathrm{N}, 26.6^{\circ} \mathrm{E}\right.$, geographic), IcelandWest $\left(63.9^{\circ} \mathrm{N}, 22.0^{\circ} \mathrm{W}\right)$, Goose Bay $\left(53.3^{\circ} \mathrm{N}, 60.5^{\circ} \mathrm{W}\right)$, Kapuskasing $\left(49.4^{\circ} \mathrm{N}, 82.3^{\circ} \mathrm{W}\right)$, and Saskatoon $\left(52.2^{\circ} \mathrm{N}, 106^{\circ} \mathrm{W}\right)$. Each of these radars consists of 16 antennas, forming a beam in 16 sequential directions (Greenwald et al., 1985). During the interval studied here the radars were operating in a mode which provided a full 16-beam scan every $\sim 100 \mathrm{~s}$, with seventy $45-\mathrm{km}$ range gates along each beam. Where common volume data were available, vector velocities were determined from the 1-o-s Doppler velocities at the intersection point of the two beams (Hanuise et al., 1993; Greenwald et al., 1995a). Large areas of backscatter echoes were recorded primarily by the CUTLASS-Finland and Iceland-West radars. At the time of the measurements these two radars were located about an hour either side of noon, both looking antisunward across the polar cap. Unfortunately they share little common volume, but they do allow a high time resolution $(\sim 100 \mathrm{~s})$ monitor of 1-o-s flow within the polar cap. Ionospheric backscatter recorded by the other radars is more limited, but by integrating over several scans to maximise the area of echoes, low temporal resolution vector velocities can be deduced.

Uncertainties in the 1-o-s velocities derived from the radar data arise for two main reasons. The first relates to the accuracy of a linear least-squares fitting to the phase of the measured complex auto-correlation function $(\mathrm{ACF})$, which results in an uncertainty in the derived Doppler velocity. This uncertainty is quantified by the 'fit' errors, which were generally less than $20 \mathrm{~m} \mathrm{~s}^{-1}$. This value is representative of the minimum error in the velocity measurements. The second uncertainty arises from the width of the measured spectrum derived from the ACF. The spectral width is principally determined by two mechanisms, the irregularity lifetime and the spread of true Doppler velocities in a given range-beam cell. Since the actual velocity must lie somewhere within the measured spectrum, the spectral width sets an upper limit on the velocity uncertainty. During the interval under study, the spectral widths at the Finland radar were typically less than $250 \mathrm{~m} \mathrm{~s}^{-1}$, whereas at IcelandWest they averaged about $300 \mathrm{~m} \mathrm{~s}^{-1}$, but with values reaching $500 \mathrm{~m} \mathrm{~s}^{-1}$. The 1-o-s uncertainties then carry 


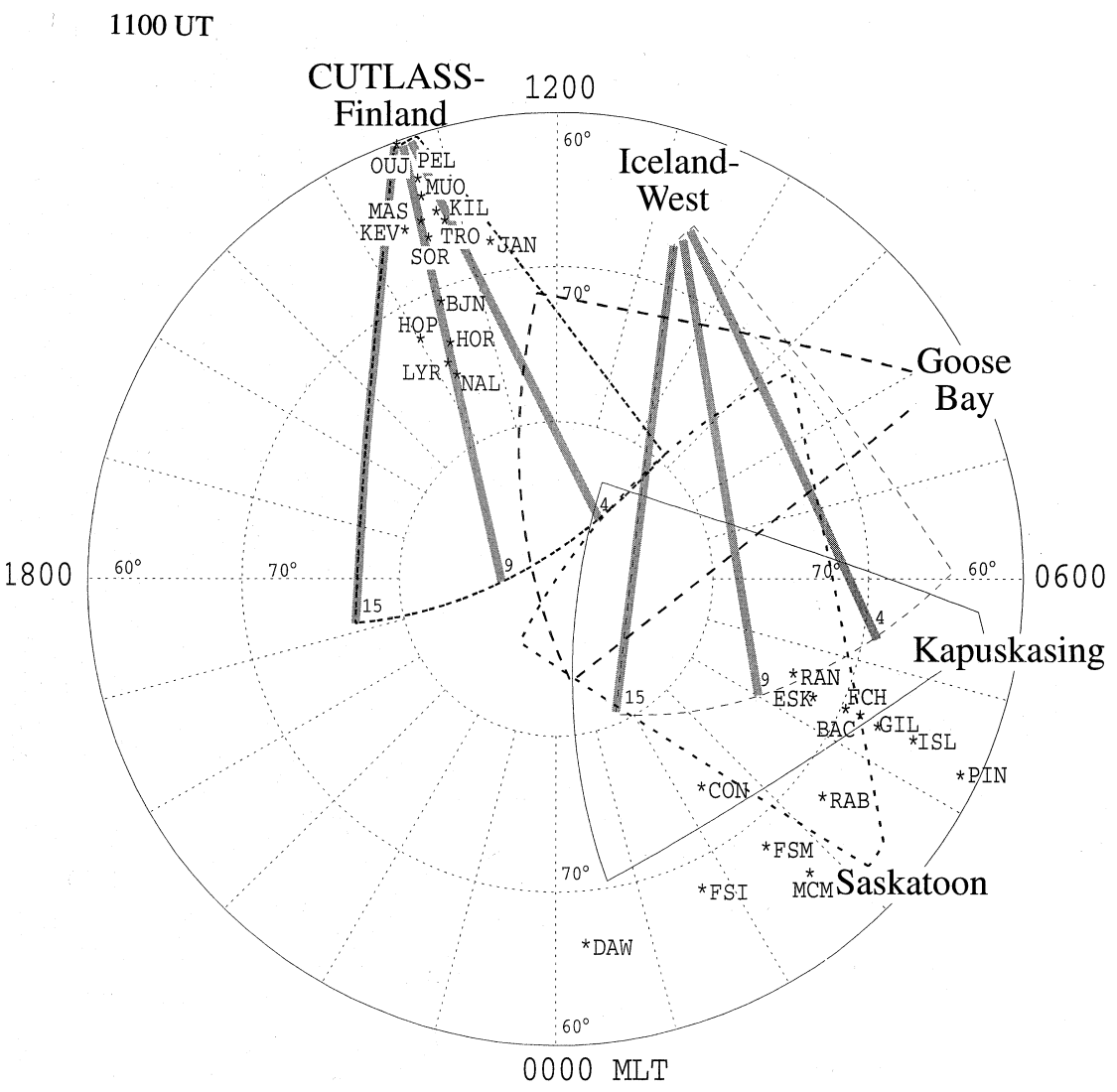

Fig. 1. Polar map illustrating the fields-of-view of the five SuperDARN radars employed in this study. The map is in AACGM latitude and local time coordinates corresponding to 1100 UT. The CUTLASS-Finland and Iceland-West beams from which data are presented in Fig. 5 are represented by thick grey lines. Also included in the figure are the locations of the magnetometer stations of the IMAGE and CANOPUS chains, data from which have been used in this study through to uncertainties in the bistatic measurements, with the fit error-associated uncertainties less than $50 \mathrm{~m} \mathrm{~s}^{-1}$ in any direction, and spectral width uncertainties in the range $300-600 \mathrm{~m} \mathrm{~s}^{-1}$.

To supplement the SuperDARN radar data, ion flow data from the DMSP-F11 satellite is used, in addition to data from selected ground magnetometer stations. Specifically, data from the IMAGE magnetometer array (Viljanen and Häkkinen, 1997) are employed to study the dayside magnetic variations under the CUTLASSFinland radar field-of-view, while data from the CANOPUS magnetometer array (Rostoker et al., 1995) in the Canadian sector are used to identify substorm onsets on the nightside. The positions of both these magnetometer arrays are shown in Fig. 1 in relation to the coverage of the SuperDARN radars.

\section{Interplanetary measurements}

During the interval studied here, the solar wind and IMF were measured upstream of the Earth by the WIND spacecraft (Ogilvie et al., 1995; Lepping et al., 1995). Figure 2 presents the solar wind plasma velocity $\left(v_{s w}\right)$ and number density $\left(N_{s w}\right)$, together with the IMF $B_{x}, B_{y}$, and $B_{z}$ components (GSM coordinates), and the total field strength $B_{t}$, for the interval 0830-1130 UT on 23 March 1995. (The grey vertical stripes correspond to SuperDARN intervals to be discussed in Sect. 6.) At the start of the interval, WIND was upstream of the Earth at GSE $X, Y, Z$ coordinates 213,39 , and $17 \mathrm{R}_{\mathrm{E}}$ respectively. At $\sim 0900 \mathrm{UT}, v_{s w}$ was $\sim 290 \mathrm{~km} \mathrm{~s}^{-1}$, and the solar wind number density $N_{s w}$ was $\sim 10 \mathrm{~cm}^{-3}$ (Fig. 2a, b). The IMF was quite stable, with $B_{x}, B_{y}$, $B_{z}$, and $B_{t}$ being approximately $0,+3,-2$, and $4 \mathrm{nT}$ respectively (Fig. 2c-f). At 0938 UT a shock propagated past the spacecraft, across which $v_{s w}$ increased to $\sim 335 \mathrm{~km} \mathrm{~s}^{-1}$, while $N_{s w}$ increased by $50 \%$ to $15 \mathrm{~cm}^{-3}$, and then slowly rose further to $25 \mathrm{~cm}^{-3}$ by $1100 \mathrm{UT}$. Simultaneously with the increase in $v_{s w}$ and $N_{s w}$, there was also an increase in the strength of the IMF, with $B_{x}, B_{y}, B_{z}$, and $B_{t}$ becoming $+2,+6,-5$, and $8 \mathrm{nT}$ respectively. The solar wind speed varied only between $\sim 330 \mathrm{~km} \mathrm{~s}^{-1}$ and $\sim 350 \mathrm{~km} \mathrm{~s}^{-1}$ for the remainder of the interval. At 1006 UT a tangential discontinuity (TD) propagated past the spacecraft, across which $B_{x}$, $B_{y}$, and $B_{z}$ changed from $+1,+8$, and $-6 \mathrm{nT}$, to $-2,-2$, and $+7 \mathrm{nT}$, i.e. the IMF changed from positive $B_{y}$ and negative $B_{z}$ to weakly negative $B_{y}$ and positive $B_{z}$. It is the ionospheric flow response to this sharp change in the direction of the IMF which is the focus of the present study.

In order to compare with the ground-based data, an estimate is required of the time at which the first effects of the IMF change would have been present in the dayside ionosphere. This delay is dependent upon $v_{s w}$, the orientation of the TD, and the position of the magnetopause and bow shock. From the empirical models of Němeček and Safránková (1991), which use the equations of Spreiter et al. (1979), the subsolar bow shock was located at $13 \mathrm{R}_{\mathrm{E}}$ prior to the northward turning, with the subsolar magnetopause at $9 \mathrm{R}_{\mathrm{E}}$. With 




Fig. 2. Data from the WIND spacecraft for the interval 08301130 UT on 23 March 1995, showing, from top to bottom, the solar wind plasma velocity, $v_{s w}$, and number density, $N_{s w}$, and the GSM components and magnitude of the IMF, $B_{x}, B_{y}, B_{z}$, and $B_{t}$. The vertical grey stripes correspond to 10 min SuperDARN data intervals shown in Fig. 6

regard to the orientation of the discontinuity it is noted that TDs are statistically aligned roughly perpendicular to the solar wind flow (Lepping et al., 1996). A variance analysis undertaken on the IMF across the TD does indeed suggest that the plane of the discontinuity was almost perpendicular to the solar wind velocity, with $X$, $Y$, and $Z$ (GSE) eigen-vectors of $0.98,0.02$ and 0.10 . With the position of the WIND spacecraft as given above, and allowing a $10^{\circ}$ uncertainty in the direction of the TD tilt and a $1 \%$ error in $v_{s w}\left( \pm 3 \mathrm{~km} \mathrm{~s}^{-1}\right)$, the plane of the discontinuity would take $63( \pm 3)$ min to travel to the subsolar bow shock. To estimate the time delay through the magnetosheath it is assumed that $v_{s w}$ fell by a factor of four across the bow shock (e.g. Spreiter et al., 1979), and then decreased linearly down to $20( \pm 5) \mathrm{km} \mathrm{s}^{-1}$ at the magnetopause (Phan et al., 1994). Allowing $\pm 10 \%$ uncertainty in the width of the magnetosheath (e.g. Spreiter and Stahara, 1980) results in a sheath travel time of $8( \pm 1) \mathrm{min}$. This gives a total delay between the measurement of the TD by WIND and its arrival at the subsolar magnetopause of
$71( \pm 4)$ min. Allowing a $3( \pm 1)$ min transit time from the magnetopause to the ionosphere [based on half the period of a typical cavity oscillation (e.g. Yeoman and Lester, 1990), consistent with the minimum ionospheric response times to changes in the IMF at the subsolar magnetopause (e.g. Todd et al., 1988)] suggests that ionospheric effects of the northward turning would be present from $1120( \pm 5) \mathrm{UT}$.

\section{Theoretical expectations}

As just indicated, we are interested here in the response of the ionospheric flow to a switch in the IMF direction from positive $B_{y}$ and negative $B_{z}$, to small $B_{y}$ and positive $B_{z}$. In a recently-published paper, Øieroset et al. (1997) have discussed the response of the cusp auroras observed near noon by a meridian scanning photometer (MSP), to just such a change in the IMF, and have proposed a picture of the flow and precipitation reconfiguration based on the theoretical ideas of Cowley and Lockwood (1992). Figure 3, taken from Fig. 7 of Oieroset et al. (1997), shows their picture in a view looking down on the Northern Hemisphere. The arrowed solid lines show the plasma streamlines, the solid lines the adiaroic open-closed field line boundary, the heavy dashed lines are the ionospheric images of the magnetopause reconnection sites, and the numbered lighter dashed lines show the loci of equal time intervals downstream from the latter, indicating the related fall in the lower cut-off energy of cusp ions with increasing time. The large arrows indicate the motions of the various boundaries. Figure 3 a shows the situation just before the first effects of the northward turn of the IMF arrive at the ionosphere, corresponding to the arrival time of the northward turn at the subsolar magnetopause plus 3 minutes. This time corresponds to $t=0$. Just prior to this time the convection takes the form of an expanding asymmetric twin-vortex flow as shown, driven by open flux tube production in the presence of positive $B_{y}$ and negative $B_{z}$. After a few minutes, open flux tube production will have ceased, while Øieroset et al. (1997) envisage a concurrent few minute delay before the northward field arrives at the high-latitude magnetopause allowing lobe reconnection to start. As shown in Fig. 3b, therefore, for the first few minutes they envisage the presence of twin cell flow decaying on a time constant of $\sim 15 \mathrm{~min}$, as the system moves towards equilibrium (Cowley and Lockwood, 1992). After a few minutes, however, lobe reconnection starts, exciting a "reversed" twin-vortex flow located between the cells of the decaying "normal" twin-vortex, as shown in Fig. 3c. The ionospheric image of the lobe reconnection site, shown by the dashed line, is formed near noon at the boundary of the region of open flux, and propagates into the polar cap, as well as expanding east and west. An expanding region of sunward flow is thereby generated in the high-latitude dayside sector, starting near the open-closed field line boundary near noon, and then expanding both polewards and eastwest. Finally, Fig. $3 \mathrm{~d}$ shows that after $\sim 15 \mathrm{~min}$ this 


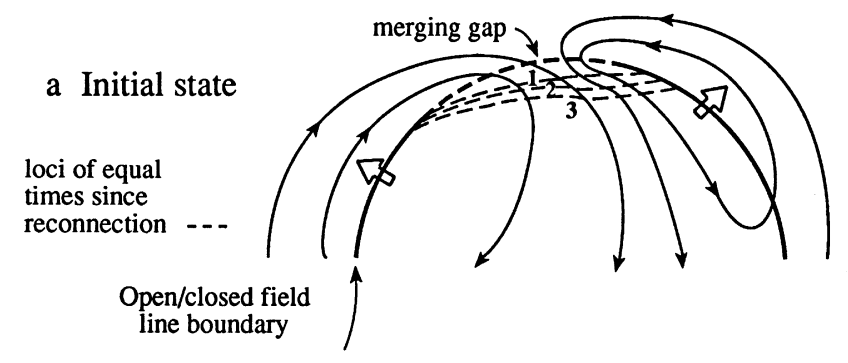

b After $\sim 4 \mathrm{~min}$
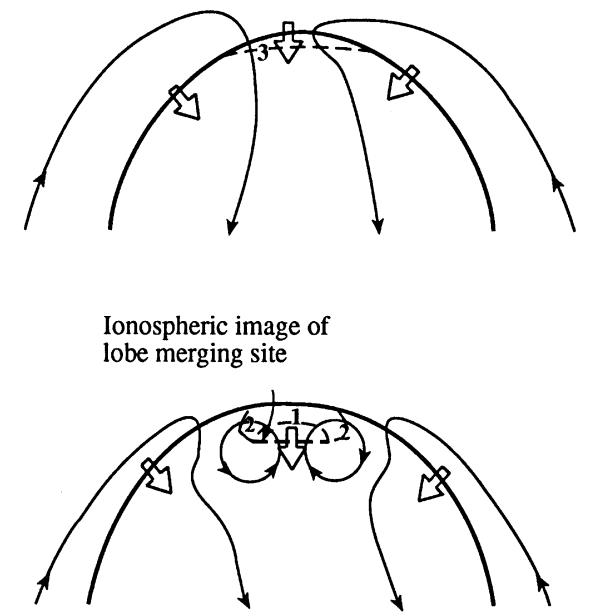

d After $\sim 12$ min $(\sim$ final state $)$

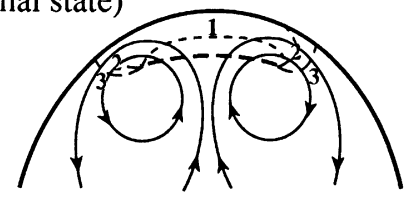

Fig. 3a-d. Sketches illustrating the expected evolution of flow in the dayside high-latitude ionosphere consequent on a change in the direction of the IMF from negative $B_{z}$ and positive $B_{y}$ to positive $B_{z}$ and near-zero $B_{y}$, taken from Fig. 7 of Øieroset et al. (1997). Arrowed solid lines are plasma streamlines, heavy solid lines are the adiaroic segments of the open-closed field line boundary, and heavy dashed lines map along the field to magnetopause reconnection sites. The numbered dashed lines indicate lines of equal time since reconnection downstream from the latter, indicating the fall of the lower cut-off energy of cusp ions as this time increases. The large arrows indicate the direction of boundary propagation

"stirring" lobe cell flow is expected to be fully established. The $\sim 15 \mathrm{~min}$ time scale is set by the time required for the reconfigured open field lines to flow from the dayside into the near-Earth tail, and for the latter to respond to that change. Additional flow cells may also be present at lower latitudes, resulting either from continued reconnection in the tail or non-reconnection "viscous" processes at the magnetopause, but these are not shown in the figure because there was no direct evidence for them in the MSP data studied by Oieroset et al. (1997). In summary therefore, this discussion proposes a prompt (few minute) response of the flow to the northward turning in the noon sector, a few minute delay in the formation of the "reversed" twin vortex relative to the onset of decay of the "normal" twin vortex, a poleward and east-west expansion of the "reversed" vortex starting at the open-closed field line boundary near noon, followed by near-steady conditions being reached after $\sim 15 \mathrm{~min}$. In the following sections we now consider the observations made on 23 March 1995, and how they relate to these expectations.

\section{Ionospheric and ground magnetic response}

This section presents an initial overview of ground magnetometer and ionospheric radar measurements. Figure 4 shows the dayside high-latitude $X$ (geographic north) magnetic component measured by the IMAGE magnetometer array during the interval 1000-1200 UT on 23 March 1995. These stations lie roughly along beam 9 of the CUTLASS-Finland radar (Fig. 1), and thus in the post-noon sector during the interval of interest here. They are presented in descending latitude with the magnetic latitude indicated in the top left hand corner of each panel. There was an impulsive negative perturbation in all magnetograms starting at $1036( \pm 1) \mathrm{min}$, which is characteristic of a sudden impulse (SI) signature (e.g. Nishida, 1978). We take this perturbation to have been produced by the interplane-

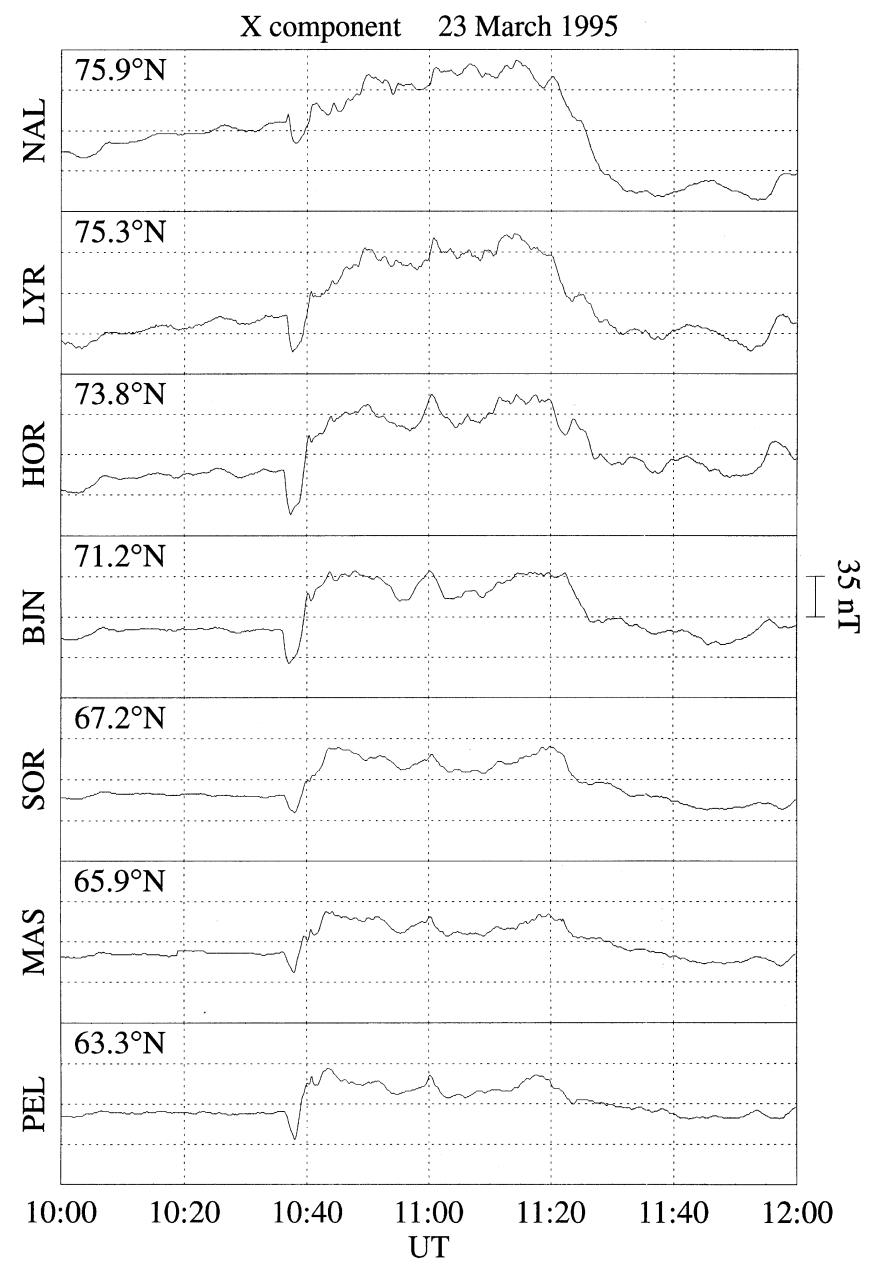

Fig. 4. The dayside $X$ component (geographic north) magnetic response measured during the interval 1000-1200 UT on 23 March 1995 by seven magnetometers of the IMAGE array 
tary shock observed by WIND at 0938 UT, such that the propagation delay from the spacecraft to the polar ionosphere was $58( \pm 1) \mathrm{min}$. We note that this delay is not at variance with our previous estimate of $\sim 74 \mathrm{~min}$ for the propagation time of the TD, due to two factors. The first is that the shock must have propagated outward from the Sun at a speed which is higher than that of the downstream (post-shock) solar wind speed, while the TD convected with the latter. Analysis of the field and plasma data indicate that the discontinuity was a quasi-perpendicular shock propagating at an angle of $\sim 20^{\circ}$ to the Earth-Sun line at a speed of $\sim 385 \mathrm{~km} \mathrm{~s}^{-1}$. The propagation speed along the Earth-Sun line was thus $\sim 410 \mathrm{~km} \mathrm{~s}^{-1}$, compared with $\sim 295 \mathrm{~km} \mathrm{~s}^{-1}$ for the pre-shock flow and $\sim 335 \mathrm{~km} \mathrm{~s}^{-1}$ for the post-shock flow. These properties are entirely typical of interplanetary shocks observed at $\sim 1$ AU (e.g. Volkmer and Neubauer, 1985). The shock propagation time from WIND to the bow shock was thus $\sim 51 \mathrm{~min}$, compared with $\sim 63 \mathrm{~min}$ for the TD. The second factor is that interplanetary shocks typically propagate across the magnetosheath with speeds which are only moderately diminished relative to upstream values, rather than being convected with the slowed plasma as for a TD (e.g. Shen and Dryer, 1972; Zhuang et al., 1981). Typical shock transit times across the magnetosheath to the subsolar magnetopause are thus only $\sim 1-2 \mathrm{~min}$, compared with $\sim 8 \mathrm{~min}$ for a TD. After reaching the magnetopause the effects of the shock are then communicated to the polar ionosphere via an Alfvénic disturbance, with a similar speed as for the effects of the TD (Tamao, 1975; Wilken et al., 1982). Using positions of the bow shock and magnetopause appropriate to preshock conditions (though this makes only a marginal difference), then leads to an estimate of the shock propagation time of $\sim 56 \mathrm{~min}$, entirely compatible with the observed interval of $58( \pm 1) \mathrm{min}$.

Following the SI, there was an increase in the $X$ component at all latitudes, with a maximum deviation of $75 \mathrm{nT}$ taking place over $7 \mathrm{~min}$ at BJN at $71^{\circ}$. Elevated $X$ components persisted for $\sim 40 \mathrm{~min}$, until at about 1120 UT the $X$ components at NAL, LYR, and HOR began to rapidly decrease, followed at 1122 UT by those at the other stations in the chain. The $Y$ (geographic east) component data (not shown) displayed relatively little change, particularly for the more poleward stations. We recall from Sect. 3 that the first effects of the TD observed by WIND at 1006 UT were estimated to have arrived at the dayside ionosphere at $1120( \pm 5) \mathrm{UT}$. It thus appears very likely that the magnetic effects observed on the IMAGE chain at this time were associated with the arrival of the TD. If the magnetic signatures were due to changes in the ionospheric flow and associated Hall current, they indicate that the onset of a reduction in westward overhead flow, or an increase in eastward flow, took place at $\sim 1120$ UT (consistent with the change in IMF $B_{y}$ from strongly positive to weakly negative across the TD), while the poleward flow was relatively unaffected at these latitudes and in this local time sector. We can also see from this data that steady magnetic conditions were resumed after $\sim 1140$ UT, that is to say after an interval of $\sim 20 \mathrm{~min}$, though the most significant changes in this meridian were complete after $\sim 10 \mathrm{~min}$.

It is also of interest to determine the occurrence of substorms during this interval. Unfortunately, magnetometer data coverage is poor in the evening sector, but postmidnight CANOPUS data (not shown) show the presence of substorm activity in the interval $\sim 1130$ 1230 UT. Specifically, $X$ component data from station DAW nearest midnight (Fig. 1) indicate onsets/intensifications of a multiple-onset disturbance at $\sim 1129,1135$, and 1146 UT. Recovery at DAW and at stations to its east (e.g. FSI and FSM) was essentially complete by $\sim 1230$ UT.

We now turn to the SuperDARN radar data, and in Fig. 5 present the 1-o-s Doppler velocity observed in six beams of the CUTLASS-Finland and Iceland-West radars (see Fig. 1 for the orientation of these beams). Apart from Fig. 5(c), the data are taken from the furthest 35 range cells and are presented as a function of range cell (left scale). Magnetic latitude is also shown (right scale), where we note that some of the IcelandWest radar beams pass through certain latitudes twice as they traverse the polar cap (Fig. 1). The top panel presents data from Iceland-West beam 4, with successive panels presenting beams located progressively anticlockwise, i.e. at generally later local times (Fig. 1). At the start of the interval, relatively few echoes were recorded in the majority of beams, with the exception of CUTLASS-Finland beam 9 (Fig. 5e). Iceland-West beams $10-15$ and CUTLASS-Finland beams 0-11 recorded echoes primarily with velocities away from the radars (negative Doppler velocities), indicating antisunward flows, while the remaining beams of each radar in the outer parts of the observed region measured Doppler velocities toward the radars (positive Doppler velocities), indicating sunward-directed flows. This pattern of 1-o-s velocities is consistent with the presence of a "normal" twin cell flow during an interval of southward IMF (Fig. 2).

The signature in the radar data of the SI is the cessation/reduction of backscatter across all beams of both radars starting at $1037 \mathrm{UT}$, possibly resulting from enhanced HF absorption caused by particle precipitation. The recovery time of the scatter varied across the beams, the quickest being at Iceland-West beam 9 (Fig. 5b), which only recorded a decrease during one scan. CUTLASS-Finland did not detect a resumption of echoes until 1046:30 UT for beam 15 (Fig. 5f), and not until 1048:00 for beam 4 (Fig. 5d). After their resumption, an increased area of returned echoes was observed compared with the pre-SI interval, together with enhanced 1-o-s flows, the highest of which exceeded $1000 \mathrm{~m} \mathrm{~s}^{-1}$ in CUTLASS-Finland beam 4 (Fig. 5d). The pattern of 1-o-s velocities, however, remained similar to before, indicative of a "normal" twin-cell flow, and this persisted for the following $\sim 40 \mathrm{~min}$.

At $\sim 1120$ UT, however, an evolution in the flow pattern started, consistent with the timing of the magnetic changes noted already, and the estimated arrival time of the effects of the TD in the dayside 


\section{SUPERDARN PARAMETER PLOT}

\section{March 1995}

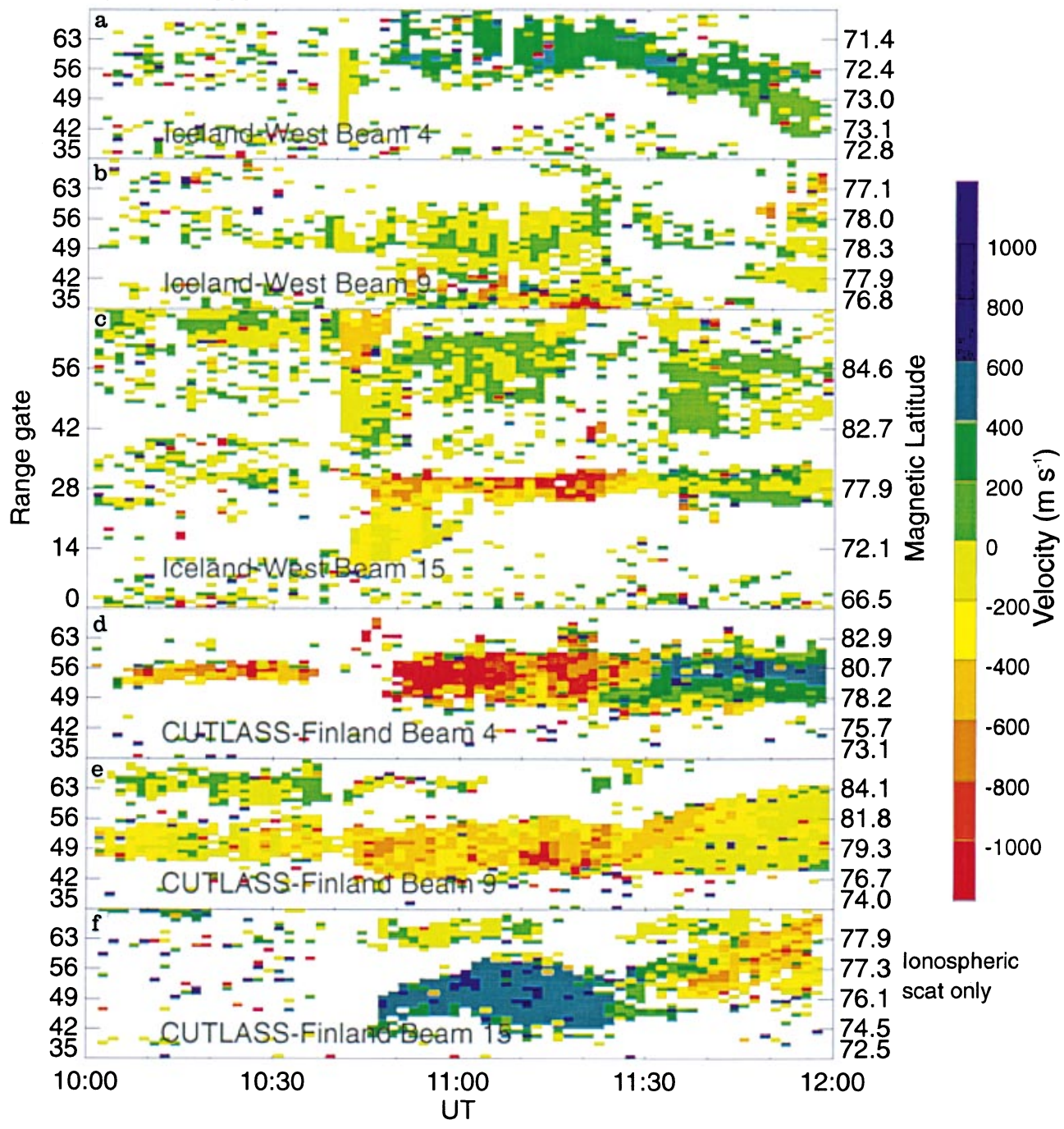

Fig. 5. Range-time-velocity plots of data from beams 4,9 , and 15 of both the Iceland-West and CUTLASS-Finland radars, the locations of which are shown (at 1100 UT) in Fig. 1. Positive values indicate l-o-s flow towards the radar

ionosphere. The main effects were observed by the CUTLASS-Finland radar, where in the western part of the radar fan near noon the flow reversed from away from the radar (antisunward) to towards the radar (sunward), as seen in the data for beam 4 (Fig. 5d). The reversal in the 1-o-s flow was first observed at $\sim 77^{\circ}$, near the equatorward edge of the region of backscatter, and then propagated poleward along the beam at $\sim 0.6 \mathrm{~km} \mathrm{~s}^{-1}$ (the propagation speed will be examined in greater detail in Sect. 7). These observations therefore indicate that sunward flows appeared in the highlatitude polar cap near noon essentially simultaneously (within the $\sim 2$ min resolution of the radar data) with the first response observed in the flow and magnetic data. We will show in more detail in Sect. 7 below that no more subtle changes in the flow which might reasonably be ascribed to the effects of the TD were observed prior to this time. In particular, there were no indications of a slowing of the "normal" twin-vortex flow speeds in the few minute interval prior to the appearance of the sunward flow, as envisaged in the theoretical discussion.
Shortly after the initial changes near noon, the flow towards the radar (sunward) in the eastern-most part of the CUTLASS-Finland $\mathrm{f}-\mathrm{o}-\mathrm{v}$ started to decline, and reversed to become away from the radar (antisunward), as seen in the data for beam 15 (Fig. 5f). This effect propagated eastward along the beam at a somewhat slower speed $\left(\sim 0.35 \mathrm{~km} \mathrm{~s}^{-1}\right.$, see also Sect. 7$)$. Relatively smaller changes in the antisunward 1-o-s flow were observed towards the centre of the radar f-o-v (e.g. for beam 9 shown in Fig. 5e), thus presumably explaining the lack of response of the $Y$ magnetic field component observed at the IMAGE chain at a similar local time. By $\sim 1140$ UT the flow had become essentially steady within the radars' $\mathrm{f}-\mathrm{o}-\mathrm{v}$, with the possible exception of CUTLASS-Finland beam 15, in which flow away from the radar gradually moved to farther ranges.

Overall, therefore, both IMAGE and SuperDARN data indicate that the effects of the TD first arrived at the dayside ionosphere at $\sim 1120 \mathrm{UT}$, in agreement with the estimate based on the propagation delay from WIND. However, consideration should be given to the possibility that the first effects could have started 
significantly earlier than this outside of the region covered by the radars and the magnetometer stations, and propagated later into their fields-of-view. This is certainly possible within the large \pm 5 min uncertainty in the estimated arrival time based on WIND data, which mainly results from the large upstream distance of the spacecraft. However, consideration of the likely displacement of where the first effects might have occurred outside of the field-of-view, and the propagation time from that position, indicates that our timing is not seriously in error relative to the basic $\sim 2 \mathrm{~min}$ resolution of the radar data. Following e.g. Øieroset et al. (1997), the first effects are expected to occur near the centre of the dayside merging gap, and to spread out from that location at typical speeds of $\sim 5 \mathrm{~km} \mathrm{~s}^{-1}$ (see also Cowley and Lockwood, 1997, and references therein to the theoretical and experimental literature). If the equatorward boundary of the dayside cusp precipitation may be taken as a reasonable proxy, then under the prevailing pre-TD IMF conditions (i.e. IMF $B_{y} \sim 8 \mathrm{nT}$ and $B_{z} \sim-6 \mathrm{nT}$ ) this is typically centred at $\sim 13$ MLT in the post-noon sector, and at $\sim 73^{\circ}$ magnetic latitude (Newell et al., 1989). Comparing this location with the position of the magnetometer stations shown in Fig. 1 (rotated to correspond to $1120 \mathrm{UT}$ rather than to $1100 \mathrm{UT}$ as shown) and the radar coverage indicated in Fig. 5, shows that the stations of the IMAGE chain at these latitudes (BJN to NAL) were located $\sim 1$ hour later in MLT (corresponding to a distance of $\sim 250 \mathrm{~km}$ ), while the equatorward edge of the radar backscatter band at this local time was located $\sim 4^{\circ}$ poleward (corresponding to a distance of $\sim 450 \mathrm{~km}$ ). At a typical phase speed of $\sim 5 \mathrm{~km} \mathrm{~s}^{-1}$ the effects of the TD would then propagate from such an initial point and be detected within $\sim 1-2 \mathrm{~min}$. This expected rapid response is also consistent with the prior studies by Etemadi et al. (1988) and Todd et al. (1988). Using EISCAT data, these authors showed that the ionospheric flow at the latitudes corresponding to magnetometer stations BJN and HOR, and at local times 12-15 MLT, responds promptly to changes in the north-south component of the IMF, with an essentially zero delay $( \pm \sim 2 \mathrm{~min})$ relative to the estimated first arrival of the effects at the ionosphere. Propagation delays of 1-2 min cannot be resolved by the flow measurements used here and do not materially effect our conclusions.

\section{Imaging ionospheric convection}

In this section we first study the form of the flow in the Northern Hemisphere which was observed during 10min intervals of relatively steady conditions on either side of the reconfiguration discussed. Our purpose is to consider in more detail the form of the flows implied by these measurements and the nature of the reconfiguration which took place. In the following section we then examine the SuperDARN data at the highest time resolution in order to investigate the temporal evolution of the flow.
Recalling from the previous section that the main interval of flow reconfiguration took place during 1120-1140 UT as implied by both the SuperDARN and magnetometer data, the 10-min intervals studied here are (a) 1020-1030; (b) 1110-1120; (c) 1140-1150; and (d) 1200-1210 UT. The flow data from these intervals are presented in Fig. 6a-d, respectively. It will be seen that intervals (b) and (c) occur immediately before and after the interval of the flow reconfiguration, respectively. Intervals (a) and (d) occur somewhat before and after these bracketting intervals, respectively, but are shown here because they coincide with DMSP overpasses, the flow observations from which are used to better define the nature of the ionospheric circulation which was occurring before and after the reconfiguration.

Figure 6 presents maps of the flow for the stated intervals in AACGM coordinates, where we show the following information:

1. Merged common volume vector velocities determined from all five SuperDARN radars (Iceland-West, Goose Bay, Kapuskasing, Saskatoon, and CUTLASS-Finland), coloured blue. The solid circle attached to each flow vector is the location of the measurement, the direction of the line represents the flow direction, and the length indicates the magnitude of the flow as indicated by the key in the figure.

2. L-o-s velocities measured by the Iceland-West and CUTLASS-Finland radars. This information is presented in two ways. First, a colour code is used to represent the direction of all the data available, brown for flow away from the radar (negative Doppler velocities), representing approximately antisunward flow, and yellow for flow towards the radar (positive Doppler velocities), representing approximately sunward flow. In addition, the magnitude of a selection of these 1-o-s velocities are represented by vectors plotted as above but coloured black. Only a selection of such vectors are shown in order to avoid congestion.

3. Ion velocity vectors measured by the DMSP-F11 spacecraft plotted as green vectors along the spacecraft track, panels (a) and (d) only, using the same scale as for the radar data.

We note that under certain circumstances magnetic perturbation vectors may also be used to obtain information about ionospheric flow speeds and directions, interpreted as being due to the effect of overhead Hall currents. However, accurate information can only be obtained if the baseline from which Hall effect perturbations are measured is reasonably well known. Unfortunately, in the present case the effect of the shock-induced field changes prior to the TD renders this process highly uncertain, such we have not felt it appropriate to use such data here.

Figure $6 \mathrm{a}$ thus shows the flows observed by the SuperDARN radars averaged over the interval 10201030 UT, together with those measured by the DMSP spacecraft in the interval 1018-1028 UT. The spacecraft overpassed the equatorward part of the radar $\mathrm{f}-\mathrm{o}-\mathrm{v}$ on 


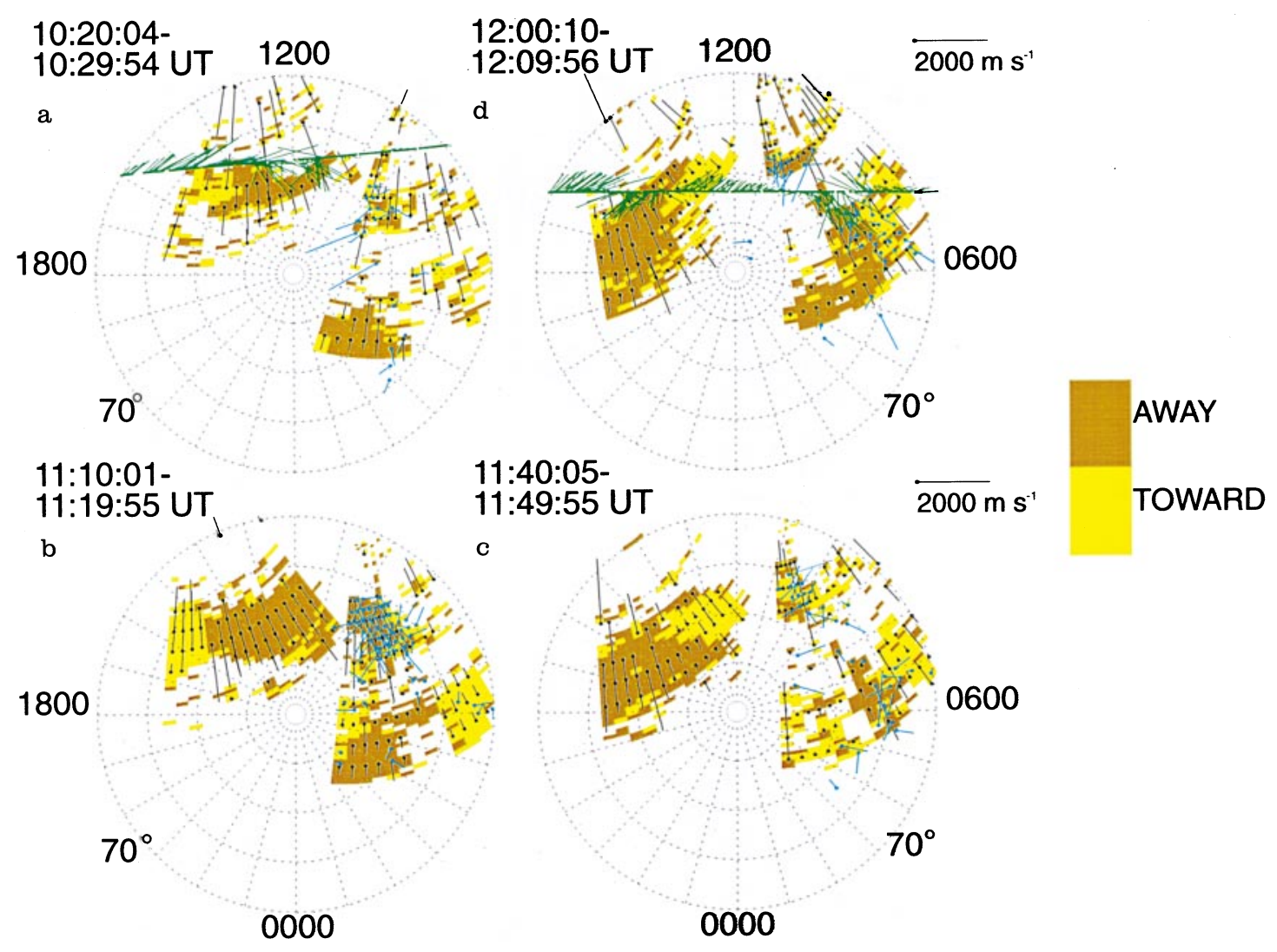

Fig. 6a-d. Ten minute-averaged polar plots in AACGM coordinates of SuperDARN and DMSP-F11 ionospheric velocity data for the intervals a 1020-1030 UT; b 1110-1120 UT; c 1140-1150 UT; and d 1200-1210 UT, on 23 March 1995. Merged vectors deduced from overlapping 1-o-s data from the five SuperDARN radars are plotted as blue symbols. The solid circle attached to each flow vector is the location of the measurement, the direction of the line represents the flow direction, and the length indicates the magnitude of the flow as

the dayside, flying from dusk to dawn. This interval preceded the occurrence of the shock-induced SI at 1036 UT, such that the timing delay estimate from WIND to the ionosphere which we calculated in Sect. 3 needs to be revised. Using the pre-shock interplanetary parameters shown in Fig. 2, we estimate on the same basis as in Sect. 3 a delay of $\sim 87$ min for interplanetary field phase fronts which are perpendicular to the EarthSun line (as seems appropriate to the small IMF $B_{x}$ value). Thus the interval $1020-1030$ UT in the ionosphere corresponds to $\sim 0853-0903$ UT at WIND, as marked by the vertical grey bar labelled interval " 1 " in Fig. 2. It can be seen, however, that the precise interval is immaterial to our discussion, due to the slowly varying nature of the interplanetary parameters around this time. During this interval the solar wind velocity, density, and field strength were all less than those observed in the period after the shock and before the TD, but the field direction was comparable, with positive $B_{y}$, negative $B_{z}$, and much smaller $B_{x}$. It may thus be expected that the form of the flow observed during this interval, if not its strength, should be similar to that which occurred after the SI, but before the arrival of the TD. Overall it can be seen that the pattern indicated by the key in the figure. L-o-s data from the CUTLASSFinland and Iceland-West radars are also represented by the colourcoding, with flow toward the radar shown as yellow areas, and flow away as brown. A selection of l-o-s vectors showing the magnitude of the l-o-s velocities are also plotted as black symbols. Flows measured along the dusk-to-dawn track of the DMSP-F11 spacecraft are presented as green vectors in a and $\mathbf{d}$, using the same scale as for the SuperDARN data

of flows observed are compatible with those expected from previous studies under these IMF conditions, as previously sketched in Fig. 3a. In particular, the SuperDARN 1-o-s data are consistent with a two-cell flow pattern, with scattered but predominantly sunward flow (yellow cells) at lower latitudes at dawn and dusk, and antisunward flow (brown cells) at higher latitudes between. The DMSP data and the merged SuperDARN data, however, show that the pattern is strongly asymmetric, with flows from dusk to dawn (westward) in the dayside near noon, reversing in direction to dawn to dusk over the central polar region. These vectors thus indicate the predominant presence of a large approximately circular clockwise "dusk" flow cell over the polar regions during this interval, as expected under the positive IMF $B_{y}$ conditions which prevailed (Fig. 3a). Evidence for the simultaneous presence of the smaller crescent-shaped "dawn" cell is rather less compelling in these data, though we note the strong eastward flows observed by DMSP just before it passed equatorwards out of the region of strong flows at 11 MLT, and the scattered sunward flows observed by SuperDARN at lower latitudes in the morning sector. 
Figure $6 \mathrm{~b}$ shows SuperDARN data in the same format for the immediate pre-reconfiguration interval 1110-1120 UT. It can be seen that the form of the flow is indeed similar to that observed in Fig. 6a, except that the twin-cell nature is now more evident, with clear regions of sunward flow (yellow cells) at lower latitudes at dawn and dusk, and predominantly anti-sunward flow (brown cells) between. These data, together with the merged vectors, also provide some evidence for continuing IMF $B_{y}$-induced asymmetry in the flow. For example, the merged vectors derived in the region of antisunward flow in the pre-noon sector all have pronounced westward flow components, consistent with the continuing $B_{y}$ positive conditions in the IMF (interval "2" marked in Fig. 2). Overall, therefore, we deduce that the flow pattern prior to the arrival of the TD was of asymmetric twin-cell form, compatible with previous observations under similar interplanetary conditions.

We now examine the nature of the flow after the reconfiguration, and first consider the interval 12001210 UT shown in Fig. 6d, when DMSP overpass data were again available (the DMSP data were taken during the interval 1200-1212 UT). Excellent agreement is observed between the DMSP and radar data, which show that a fundamental change had occurred in the flow pattern, with the appearance of a region of flow with a sunward component on the dayside near noon, as expected from the discussion in the previous section. Overall, the flow was clearly multi-celled, with the usual pattern of twin-vortex flow at lower latitudes augmented by an additional clockwise vortex within the central polar region, centred in the pre-noon sector. Whether a smaller fourth anticlockwise polar cell was also present post-noon (as sketched in Fig. 3d) is not simply determinable from these data. Overall, this pattern of flow is that expected for positive IMF $B_{z}$ in the additional presence of positive $B_{y}$. The IMF data measured by WIND during the corresponding interval (marked " 4 ", in Fig. 2), show a strong positive $B_{z}$ component, but only a small $(\sim 1 \mathrm{nT})$ and varying (generally) positive $B_{y}$. We note, however, that WIND was displaced $\sim 43 \mathrm{R}_{\mathrm{E}}$ from the Earth-Sun line during this period, so that the field which it observed may not have been representative in detail of that which impinged on the sub-solar magnetopause.

Turning finally to the immediate post-reconfiguration flow shown in Fig. 6c, we note that the SuperDARN radar data is essentially similar to that just discussed, and thus indicative of a multi-celled pattern. Specifically, moving from dawn to dusk, we observe a region of sunward flow (yellow cells) at lower latitudes in the morning sector, which is flanked by a region of antisunward flows (brown cells) at higher latitudes. A substantial patch of sunward flow is then present at high latitudes near noon, flanked on the duskward side by another region of antisunward flow. Finally, a few scattered sunward flow cells remain present at low latitudes on the dusk side, which we may identify as the vestiges of the usual low-latitude sunward return flow by comparison with Fig. 6d. We note that the IMF direction measured by WIND during the corresponding interval (interval " 3 " in Fig. 2) was almost the same as in interval " 4 " just discussed, except that the IMF $B_{y}$ component was small and negative. The possibility thus exists that the asymmetry in the central polar cells during this interval differed in detail from that of Fig. 6d, but this is not of major significance for the discussion here.

In summary, therefore, these data indicate that after the arrival of the TD at the dayside magnetopause, the high-latitude flow reconfigured from a distorted twincell flow to a multi-cell flow within an interval of 20 min. The "before" and "after" flows are generally compatible with those anticipated in Fig. 3a and 3d, though there appears to be more $B_{y}$-related flow asymmetry in the "after" flows than might have been anticipated from the IMF data measured by WIND. Lower-latitude flow cells also remained present in the "after" configuration, presumably maintained by the nightside substorm activity observed in the interval 1130-1230 UT, which was noted above. If we now compare the SuperDARN flows in the bracketing "before" and "after" intervals, shown in Fig. 6b and $6 \mathrm{c}$ respectively, it can be seen that the principal change was the appearance of a patch of sunward-directed flow near noon, in a region where the flow had originally been antisunward. In addition, the region of antisunward flow flanking this region on the dusk side had moved to lower latitudes, such that the region of duskside sunward flow had moved nearly wholly out of the radar's f-o-v. In the next section we will consider the radar data at the highest time resolution during the interval of the reconfiguration to examine how these changes occurred.

\section{High time resolution observations of the flow reconfiguration}

In Fig. 7 we show maps of the high-latitude flow on a scan-by-scan basis for the interval of the reconfiguration, 1120-1140 UT. The format is the same as for Fig. 6, except we have now added a third category of colour coding for the l-o-s radar data. Because the uncertainties are rather larger in these unaveraged measurements, we indicate the data for which the direction of flow towards/away from the radar is uncertain by the grey shading [the specific criterion is $\mid$ velocity $\mid<$ (spectral width)/2]. In addition, since essentially no merged vectors were available during the interval, discussion here will centre on the l-o-s velocities.

In the first scan, starting at 1120:01 UT, the overall flow is very similar to that shown previously in the averaged "before" map shown in Fig. 6b, as may be expected. However, examination of subsequent data shows that an enduring change began during this scan (to be substantiated further later), in which a small region of sunward flow was observed in the immediate post-noon sector $(\sim 1230 \mathrm{MLT})$ at the lowest latitudes from which backscatter was observed $\left(\sim 77^{\circ}\right)$. In subsequent scans this region expanded rapidly in local time 


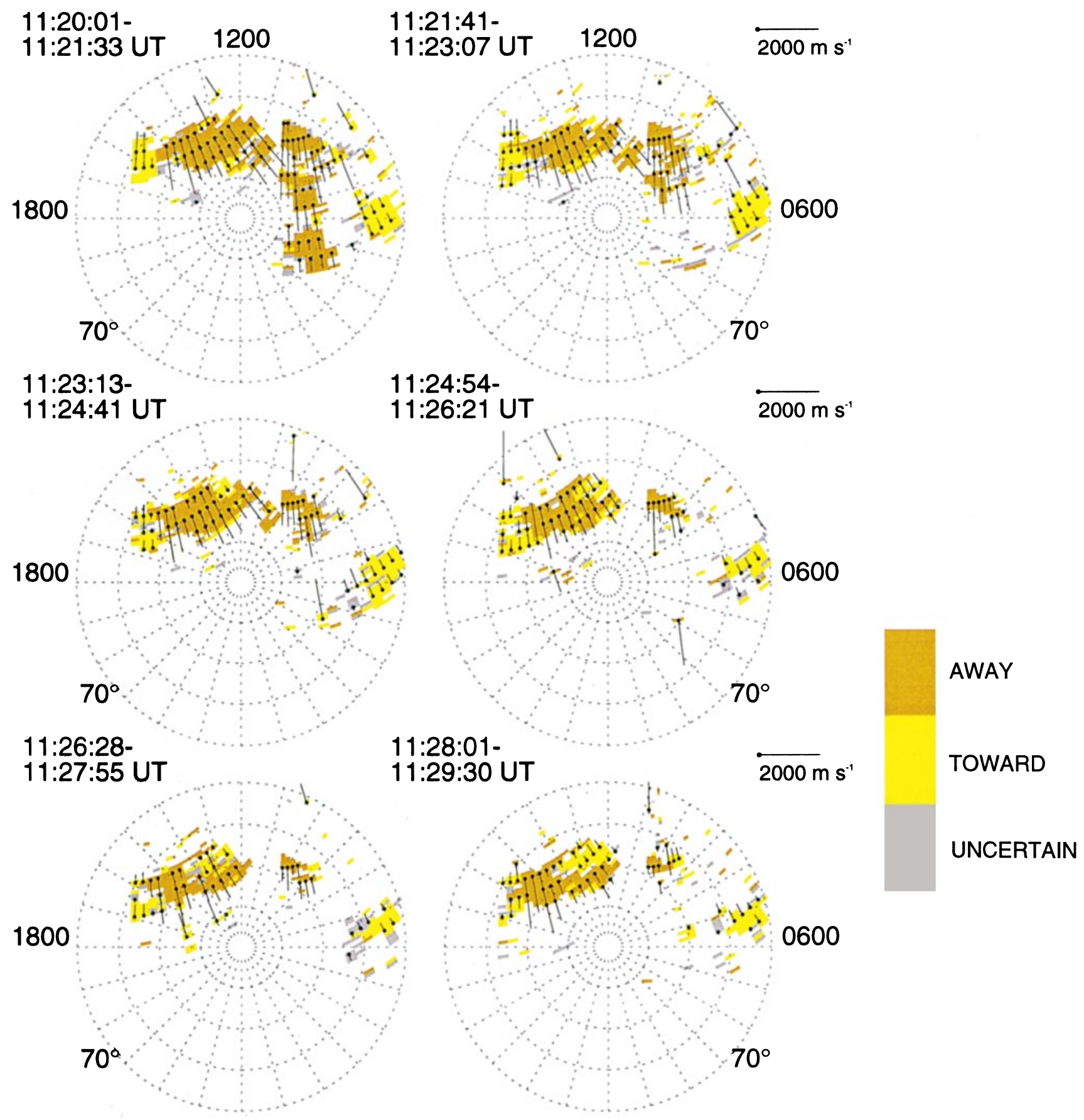

Fig. 7. Polar plots of SuperDARN radar flow data shown on a scanby-scan basis during the interval of flow reconfiguration, 11201140 UT. The format is the same as for Fig. 6, except that the grey

towards both dusk and dawn, though its progress towards dawn cannot be followed far due to the westward limitation of the $\mathrm{f}-\mathrm{O}-\mathrm{v}$ of the CUTLASSFinland radar. In its progress towards dusk, the region had reached beam 8 of the radar at $\sim 1415$ MLT (at $\sim 78^{\circ}$ latitude) by the scan starting at 1126:28 UT, and there its eastward expansion halted. The region also cells indicate areas in which the flow direction toward or away from the radar was uncertain, i.e. for which $\mid$ velocity $\mid<$ (spectral width) $/ 2$

expanded polewards, reaching $\sim 82^{\circ}$ at noon (at or near the most poleward extent of the region of backscatter) by the scan starting at 1132:48 UT. After this, the region of sunward flow within the f-o-v evolved much more slowly with time.

A complementary view of this evolution is shown in Fig. 8, where we show the 1-o-s velocity plotted versus 


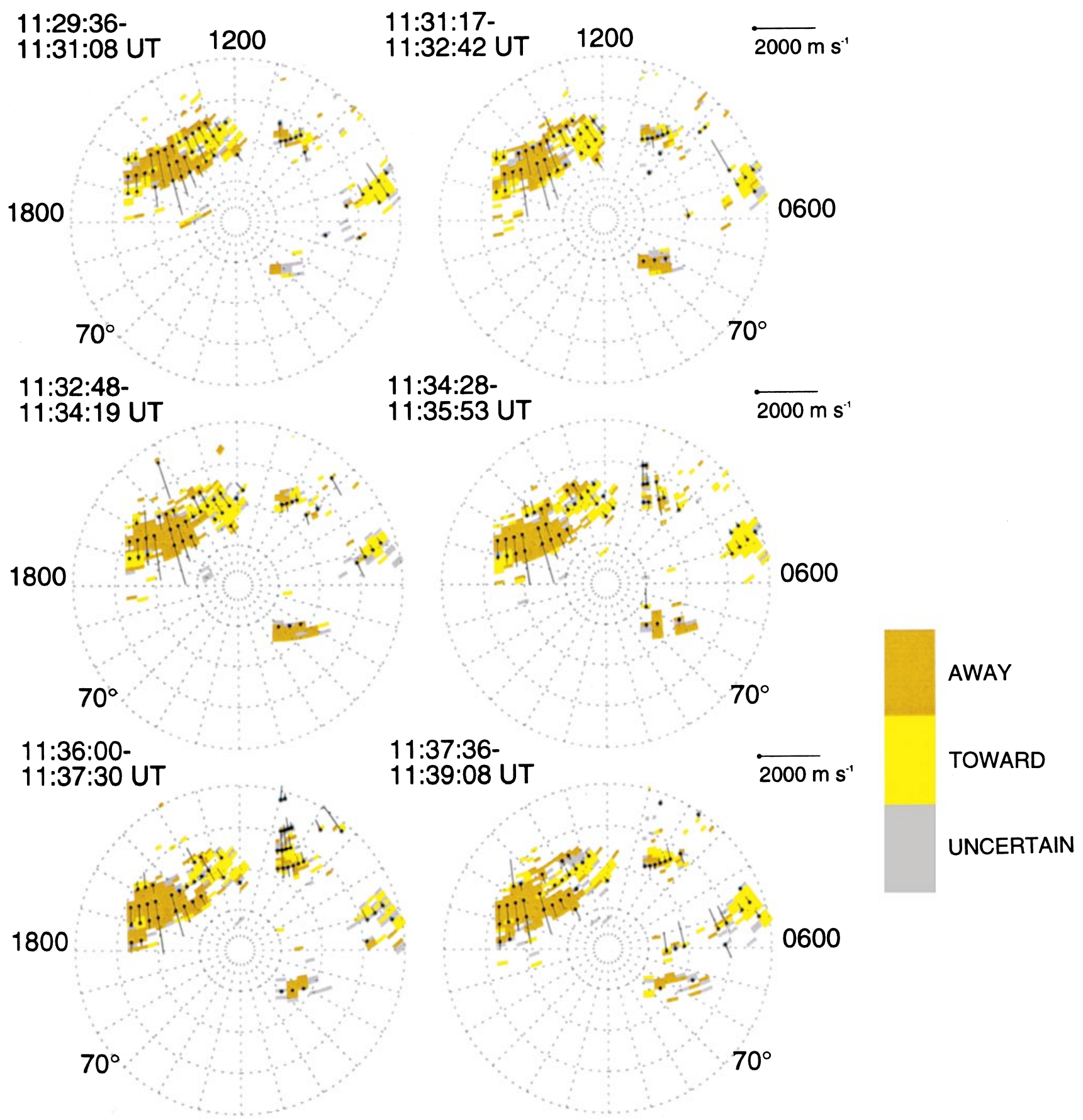

Fig. 7 (continued)

time for several selected beams and ranges of the CUTLASS-Finland radar. Each line corresponds to an average of the 1-o-s velocities measured in two adjacent beams and two adjacent range cells (i.e. an average of four values), in order to reduce the uncertainties in the individual measurements. The sudden appearance of sunward flow near noon at $\sim 1120$ UT (vertical dashed line) and its subsequent poleward propagation is shown in Fig. 8a. The upper panel shows data for beams 2-3 on the western edge of the radar fan (little data was obtained in beams 0 and 1), for range gates 48-49 (solid square), 50-51 (solid circle), 52-53 (solid triangle), 5455 (open circle), and 56-57 (open square), over the interval 1110-1150 UT. The local time of the centres of these cell clusters was $1200( \pm 16 \mathrm{~min}) \mathrm{MLT}$ at 1120 UT, while their magnetic latitudes spanned the range $77.1^{\circ}-79.5^{\circ}$ (detailed position data for the centres of relevant 4-point cell clusters is given in Table 1, where 
Ranges: 48-49 ( . ); 50-51 (• ); 52-53 ( ^ ); 54-55 ( o ); 56-57( 口)
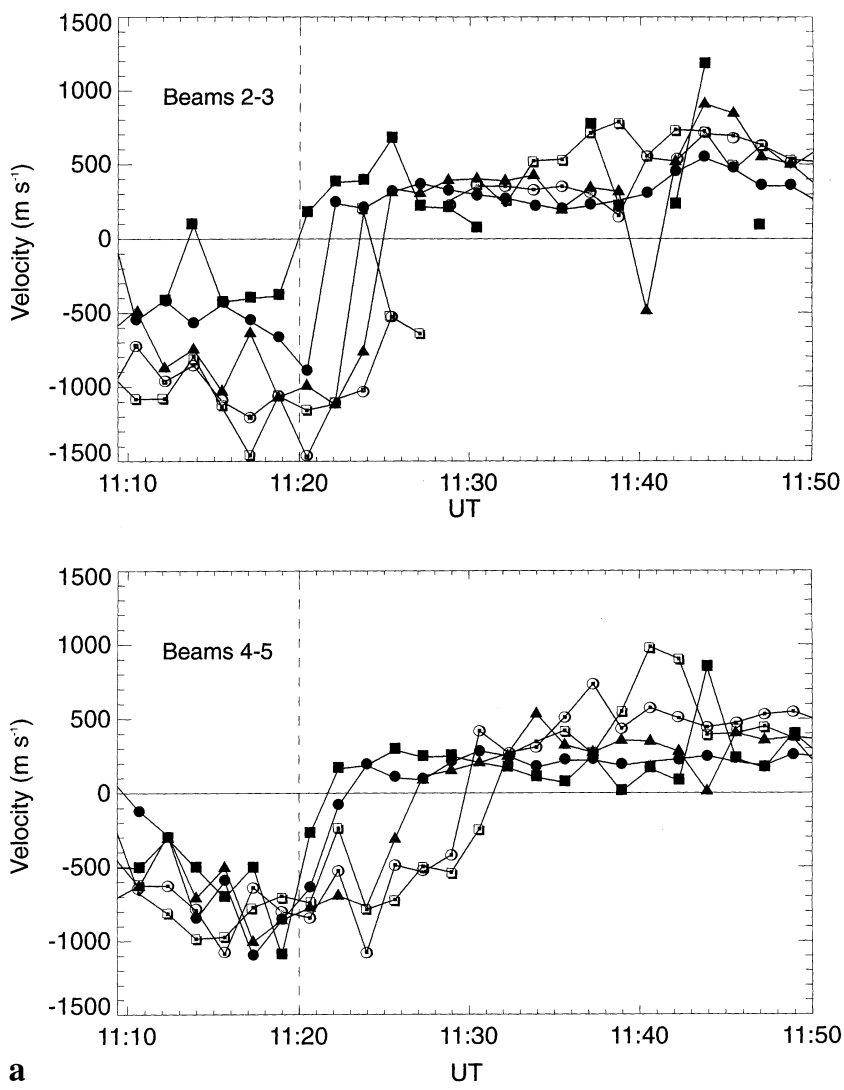

SUPERDARN PARAMETER PLOT

23 Mar 1995

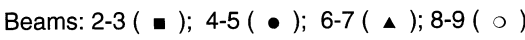

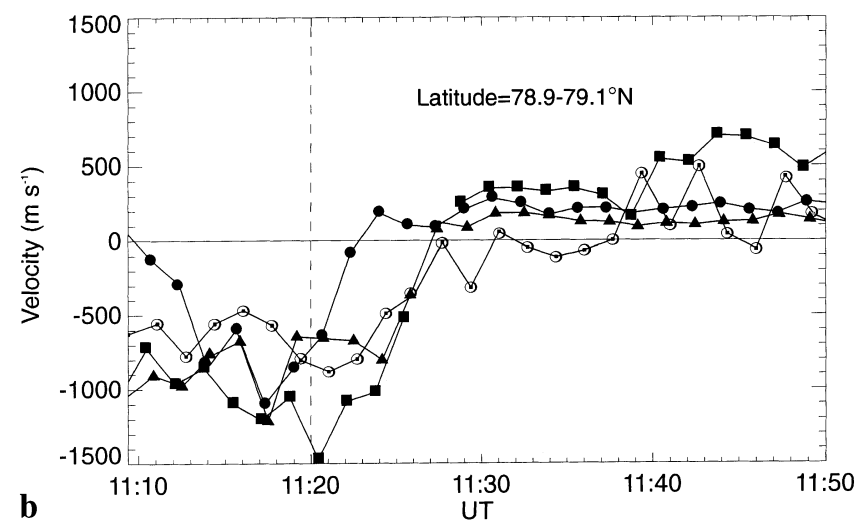

Fig. 8a-c. Time series plots of the averaged 1-o-s velocities observed in selected 4-cell clusters of CUTLASS-Finland radar data, corresponding to two adjacent range gates along each of two adjacent radar beams. The time interval for each plot is 1110-1150 UT, and the dashed vertical line at 1120 UT represents the start of the $20 \mathrm{~min}$ interval of flow reconfiguration. Positive 1-o-s velocities indicate flow towards the radar (approximately sunward), while negative velocities indicate flows away from the radar (approximately antisunward). a Shows data from successive range gate pairs of beams 2-3 (upper panel) and 4-5 (lower panel), showing the poleward progression of the flow transition from antisunward to sunward flow in the noon sector.
Ranges: 48-49 ( a ); 50-51 ( • ); 52-53 ( • ); 54-55 ( o )
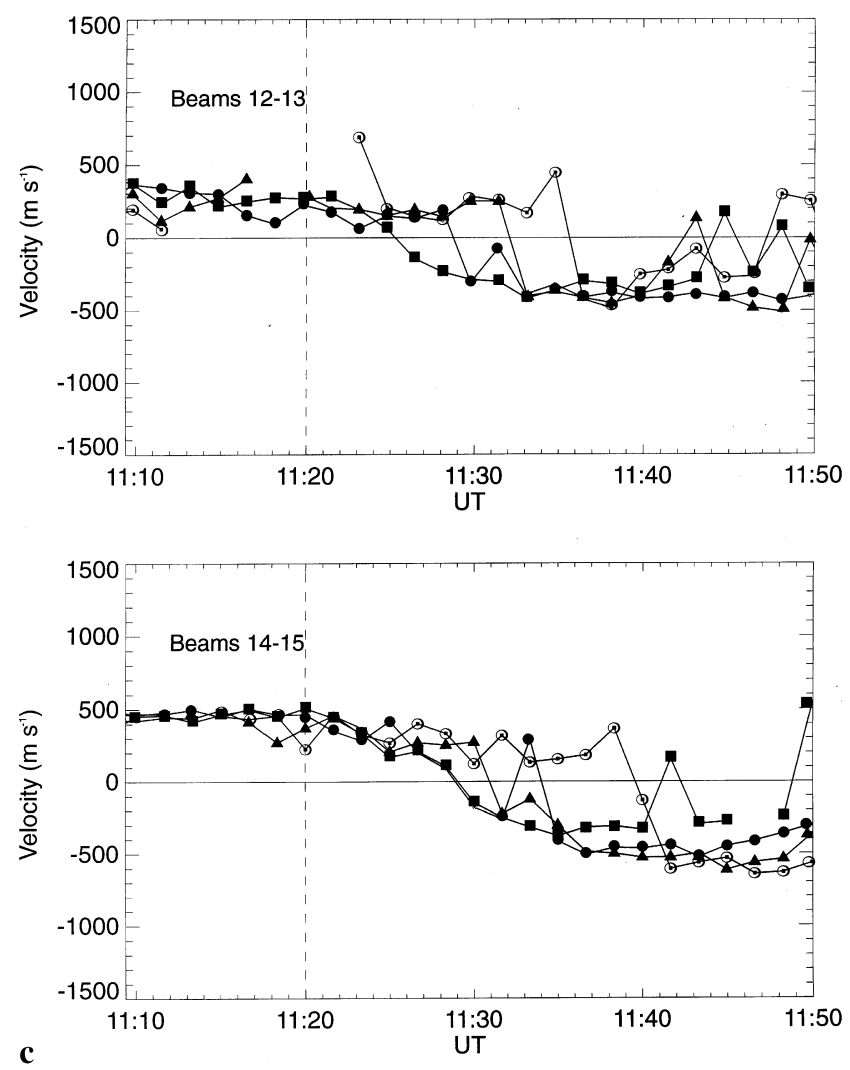

c

b Shows data obtained for cell clusters centred in the magnetic latitude band $78.9^{\circ}-79.1^{\circ}$ at various local times in the noon sector, showing the east-west propagation of the antisunward-to-sunward flow transition; specifically the data are for beams 2-3 ranges 54-55 (solid square), beams 4-5 ranges 50-51 (solid circle), beams 6-7 ranges 48-49 (solid triangle), and beams 8-9 ranges 48-49 (open circle). c Shows data from successive range gate pairs of beams 12-13 (upper panel) and 14-15 (lower panel), showing the eastward motion of the sunward-to-antisunward flow transition observed in the eastern part of the radar f-o-v in the pre-dusk sector 
Table 1. AACGM latitude and local time of the centres of 4-cell clusters of measurement points within the CUTLASS-Finland radar field of view relevant to this study. The clusters correspond to

\begin{tabular}{llllllll}
\hline Range cells & Beam 2-3 & Beams 4-5 & Beams 6-7 & Beams 8-9 & Beams 10-11 & Beams 12-13 & Beams 14-15 \\
\hline $48-49$ & $77.1^{\circ} \mathrm{N}$ & $78.3^{\circ} \mathrm{N}$ & $79.0^{\circ} \mathrm{N}$ & $79.1^{\circ} \mathrm{N}$ & $78.7^{\circ} \mathrm{N}$ & $77.7^{\circ} \mathrm{N}$ & $76.4^{\circ} \mathrm{N}$ \\
& $12: 17 \mathrm{MLT}$ & $12: 50 \mathrm{MLT}$ & $13: 30 \mathrm{MLT}$ & $14: 13 \mathrm{MLT}$ & $14: 55 \mathrm{MLT}$ & $15: 27 \mathrm{MLT}$ & $15: 53 \mathrm{MLT}$ \\
$50-51$ & $77.7^{\circ} \mathrm{N}$ & $79.0^{\circ} \mathrm{N}$ & $79.8^{\circ} \mathrm{N}$ & $79.9^{\circ} \mathrm{N}$ & $79.3^{\circ} \mathrm{N}$ & $78.3^{\circ} \mathrm{N}$ & $76.8^{\circ} \mathrm{N}$ \\
& $12: 10 \mathrm{MLT}$ & $12: 46 \mathrm{MLT}$ & $13: 30 \mathrm{MLT}$ & $14: 18 \mathrm{MLT}$ & $15: 03 \mathrm{MLT}$ & $15: 39 \mathrm{MLT}$ & $16: 05 \mathrm{MLT}$ \\
$52-53$ & $78.3^{\circ} \mathrm{N}$ & $79.7^{\circ} \mathrm{N}$ & $80.6^{\circ} \mathrm{N}$ & $80.6^{\circ} \mathrm{N}$ & $80.0^{\circ} \mathrm{N}$ & $78.8^{\circ} \mathrm{N}$ & $77.2^{\circ} \mathrm{N}$ \\
& $12: 03 \mathrm{MLT}$ & $12: 41 \mathrm{MLT}$ & $13: 30 \mathrm{MLT}$ & $14: 24 \mathrm{MLT}$ & $15: 13 \mathrm{MLT}$ & $15: 52 \mathrm{MLT}$ & $16: 18 \mathrm{MLT}$ \\
$54-55$ & $78.9^{\circ} \mathrm{N}$ & $80.5^{\circ} \mathrm{N}$ & $81.3^{\circ} \mathrm{N}$ & $81.4^{\circ} \mathrm{N}$ & $80.6^{\circ} \mathrm{N}$ & $79.3^{\circ} \mathrm{N}$ & $77.5^{\circ} \mathrm{N}$ \\
& $11: 54 \mathrm{MLT}$ & $12: 35 \mathrm{MLT}$ & $13: 30 \mathrm{MLT}$ & $14: 31 \mathrm{MLT}$ & $15: 25 \mathrm{MLT}$ & $16: 05 \mathrm{MLT}$ & $16: 32 \mathrm{MLT}$ \\
$56-57$ & $79.5^{\circ} \mathrm{N}$ & $81.2^{\circ} \mathrm{N}$ & $82.1^{\circ} \mathrm{N}$ & $82.1^{\circ} \mathrm{N}$ & $81.2^{\circ} \mathrm{N}$ & $79.7^{\circ} \mathrm{N}$ & $77.8^{\circ} \mathrm{N}$ \\
& $11: 44 \mathrm{MLT}$ & $12: 29 \mathrm{MLT}$ & $13: 30 \mathrm{MLT}$ & $14: 39 \mathrm{MLT}$ & $15: 39 \mathrm{MLT}$ & $16: 21 \mathrm{MLT}$ & $16: 47 \mathrm{MLT}$ \\
\hline
\end{tabular}

two adjacent range cells along each of two adjacent beams. The local times correspond to $1120 \mathrm{UT}$, the start of the interval of flow transition all local times refer to $1120 \mathrm{UT}$ ). The lowest latitude gate shown corresponds to the equatorward edge of the backscatter band at this local time. It can be seen that a sharp transition from flows away from the radar (negative values) to flows towards the radar (positive values) took place in each cell cluster shown. In the lowest latitude data, gates $48-49\left(77.1^{\circ}\right)$, the transition occurred in the measurement immediately following 1120 UT, corresponding to the first scan shown in Fig. 7, thus substantiating our claim above that enduring sunward flows were first observed during this scan. The transition was then observed later at higher latitudes, reaching gates $52-53\left(78.3^{\circ}\right)$ shortly after 1125 UT. The times of the transitions for gates $54-57$ are clearly later than this, but their exact values cannot be determined due to data gaps. A similar polewardpropagating flow transition is shown in the lower panel of the figure for beams 4-5 and the same range gates as already mentioned. These cell clusters were located at 1240 ( $\pm 10 \mathrm{~min}) \mathrm{MLT}$ at $1120 \mathrm{UT}$, and spanned the magnetic latitude range $78.3^{\circ}-81.2^{\circ}$ (Table 1 ). The transition was observed just after 1122 UT in the lowest latitude cell cluster, and at 1132 UT in the highest. The poleward propagation speed of the transition implied by these delays is $\sim 0.6 \mathrm{~km} \mathrm{~s}^{-1}$ in this local time sector, as previously indicated in Sect. 5. Overall, this expansion was sustained during an interval of $\sim 14$ min to cover an observed magnetic latitude range of $\sim 5^{\circ}$.

The longitudinal propagation is shown in Fig. 8b, where we show similar plots for four cell clusters which lie at a common magnetic latitude of $78.9^{\circ}-79.1^{\circ}$. These are beams 2-3 ranges 54-55 (solid square), beams 4-5 ranges 50-51 (solid circle), beams 6-7 ranges 48-49 (solid triangle), and beams 8-9 ranges 48-49 (open circle). At 1120 UT these lie at 1154, 1246, 1330, and 1413 MLT respectively, thus spanning a little over two hours of local time in the immediate post-noon sector (Table 1). It can be seen that at this latitude, sunward flows were first observed in the post-noon cells corresponding to beams $4-5$ at $\sim 1124$ UT. The transition then occurred later at both earlier and later local times. The transition occurred after $\sim 1126$ UT in beams $2-3$ (made somewhat uncertain by the data gap), at $\sim 1127$ UT in beams $6-7$, and at $\sim 1128-1131$ UT in beams 8-9 (though the 1-o-s flow in the latter beams approaches zero in this interval rather than actually reversing to sunward). The implied eastward expansion speed of the flow transition was thus $\sim 1.5 \mathrm{~km} \mathrm{~s}^{-1}$, which overall was sustained during an interval of $\sim 7 \mathrm{~min}$ to cover a longitudinal extent of $\sim 2 \mathrm{~h} \operatorname{MLT}(\sim 650 \mathrm{~km})$ eastward of noon at the lower latitudes observed. The probable simultaneous westward expansion into the prenoon sector was not well monitored by the radars during this interval, due to f-o-v limitations.

Figure 8a, b also demonstrates that no consistent changes in the near-noon flow took place within the radar f-o-v prior to $1120 \mathrm{UT}$ which might reasonably have been due to the effect of the TD. Specifically, no consistent slowing of the antisunward flow is discernible over the previous few-minute interval before the first appearance of sunward flow, as was anticipated in the theoretical discussion. Indeed, the trend instead is towards increasing 1-o-s speeds over the prior $\sim 10 \mathrm{~min}$ interval, as can also be seen more generally in Fig. 5.

The second major change in the l-o-s flows observed during the interval 1120-1140 UT was the transition from sunward to anti-sunward flow in the further ranges of the most eastern beams $(12-15)$ of the CUTLASSFinland radar (Fig. 6b, c). The scan-by-scan flow maps displayed in Fig. 7 show that the flow in the nearest ranges of these beams in which backscatter was observed (at $\sim 1600$ MLT and $\sim 75^{\circ}$ latitude) remained persistently sunward throughout, consistent with the sunward flow in the lower-latitude dusk flow cell observed later by DMSP (see Fig. 6d). However, with the scan starting at 1124:54 UT the flow at further ranges changed from sunward to antisunward, an effect which propagated to increasing ranges along the beams with time, corresponding mainly to an eastward motion of the transition towards the dusk meridian. By the time of the final scan shown in Fig. 7 starting at 1137:36 UT, sunward flows in the further ranges of these beams had all but disappeared, such that the pattern of 1-o-s flows was then essentially the same as the averaged "after" pattern shown in Fig. 6c.

This eastward propagation is also shown in the timeseries plots in Fig. 8c. Here the upper panel shows the 1-o-s velocity for beams 12-13 and ranges 48-49 (solid square), 50-51 (solid circle), 52-53 (solid triangle), and 54-55 (open circle). These cell clusters were centred at a 
latitude of $\sim 78.5^{\circ}$, and at 1120 UT spanned the local time range 1527-1605 MLT (Table 1). The transition from sunward to antisunward flow took place at $1125 \mathrm{UT}$ at the nearest range, and at later times at further ranges, increasing to $1136 \mathrm{UT}$ at the furthest range shown. The lower panel shows corresponding results for the same ranges along beams 14-15. These cell clusters are centred at a latitude of $\sim 77^{\circ}$, and at $1120 \mathrm{UT}$ spanned a local time range of 1553-1632 MLT. The flow transition took place at 1129 UT at the nearer ranges, increasing to $\sim 1140$ UT at the furthest ranges shown. The eastward phase speed of the flow transition implied by these data is $\sim 0.35 \mathrm{~km} \mathrm{~s}^{-1}$, as previously mentioned in Sect. 5. Again, no systematic flow changes were observed in these data prior to 1120 UT.

\section{Summary and discussion}

In this work we have used SuperDARN and DMSP velocity data, and ground-based magnetometer data, to study the response of the dayside ionospheric flow to a sharp switch in the direction of the IMF (a TD) measured upstream of the Earth by the WIND spacecraft, from negative $B_{z}$ and positive $B_{y}$, to positive $B_{z}$ and small $B_{y}$. It has been shown that the initial and final states of the flow are in broad conformity with expectations based on these field directions. In the initial state with negative $B_{z}$ and positive $B_{y}$, the data are consistent with a twin-cell flow distorted by $B_{y}$ effects, with westward and poleward flows present at high latitudes near noon, and return sunward flows at lower latitudes at dawn and dusk. After the flow transition had taken place the flow was multi-celled, with a large area of sunward flow present at high latitudes near noon, indicative of the presence of one or more "lobe" convection cells, flanked at lower latitudes by continuing twin-cell flow, possibly maintained by concurrent nightside substorm activity. The radar data have then been studied at the highest time resolution available $(\sim 2 \mathrm{~min})$ to determine how this flow transition took place.

The radar and magnetometer data show that the onset of changes in the flow in the dayside ionosphere was concurrent with our best estimate of the time at which the effects of the change in the IMF could first have reached the ionosphere. This detailed agreement is probably fortuitous because of the large estimated uncertainty in the latter time $( \pm 5 \mathrm{~min})$, but these data do confirm previous results that the response time near noon at these latitudes is short, just a few minutes at most. Our results show in addition, however, that sunward flows were present immediately after the change started (within $\sim 2 \mathrm{~min}$ ), observed here in a small post-noon patch at the equatorward edge of the radar backscatter band at $77^{\circ}$. No consistent changes in flow which could reasonably be ascribed to the effects of the TD were observed within the radar f-o-v in the prior interval, nor any consistent magnetic signatures. In particular, no prior slowing of the initial twin-vortex flow was observed, as anticipated in previous theoretical discussion. Although our observational coverage of the relevant regions of the dayside ionosphere is not complete, possible propagation delays from likely onset positions outside the region covered are estimated to be no more than 1-2 min, such that our conclusions are unlikely to be significantly effected by this factor.

With increasing time the patch of sunward flow expanded west and east, with the latter motion being best studied due to limitations in the radar $\mathrm{f}-\mathrm{O}-\mathrm{v}$ to the west. The eastward expansion speed was $\sim 1.5 \mathrm{~km} \mathrm{~s}^{-1}$, which was sustained for an interval of $\sim 7$ min after the start of the transition to carry the region of sunward flows $\sim 2 \mathrm{~h}$ MLT past noon towards dusk. The region of sunward flow also expanded poleward at $\sim 0.6 \mathrm{~km} \mathrm{~s}^{-1}$, a motion which was sustained for $\sim 14 \mathrm{~min}$, such that it then reached near to the poleward border of the backscatter band at $\sim 82^{\circ}$. After this time the region of sunward flows evolved much more slowly with time within the radar f-o-v. The radars also detected a change in the flow at lower latitudes in the dusk sector, where sunward flows changed to antisunward starting $\sim 5 \mathrm{~min}$ after the beginning of the transition. This change propagated eastward out of the $\mathrm{f}-\mathrm{o}-\mathrm{V}$ after a further $15 \mathrm{~min}$. The overall time taken for the flow to reconfigure within the radar $\mathrm{f}-\mathrm{O}-\mathrm{V}$ was thus $\sim 20 \mathrm{~min}$.

If we now compare these findings with the expectations outlined in Sect. 4 and illustrated in Fig. 3, based on the discussion of Øieroset et al. (1997), we find a number of striking similarities, and one real difference already mentioned. The similarities are as follows. First, we find a prompt response of the dayside flow to the change in the IMF, with first effects being observed within a few minutes of the time at which it first could have responded. However, the limits on the response time are not very stringent $( \pm 5 \mathrm{~min})$ in the present study because of the large upstream distance of the monitoring spacecraft and the consequent relatively large uncertainty in the propagation time. Second, sunward flow was first observed at lower latitudes near noon, and propagated polewards and east-west, implying an initial poleward and east-west propagation of the image of the lobe reconnection site in the ionosphere, as in the picture presented by Øieroset et al. (1997) (see Fig. 3c, d). The fact that the region of sunward flow was first seen near the equatorward edge of the radar backscatter band may also be significant. Recent studies with the CUTLASS radars have indicated that, very often, the equatorward edge of the backscatter band near noon closely corresponds to the equatorward edge of the $630 \mathrm{~nm}$ cusp optical emission, and hence to a location near the open-closed field line boundary (Yeoman et al., 1997; Milan et al., 1998). We have no independent way of verifying whether this is true for the data presented here, and we note that the latitude of the edge of the backscatter band $\left(\sim 77^{\circ}\right)$ was significantly higher than the average location of the cusp precipitation under the prevailing IMF conditions $\left(\sim 73^{\circ}\right)$ as determined by Newell et al. (1989). But if it is the case, the implication is that the region of sunward flow started near the open-closed field line boundary, and propagated poleward from there, as predicted by Øieroset et al. (1997). This aspect requires further study 
and verification. Third, the region of sunward flow evolved rapidly towards more steady conditions over an interval of $\sim 14 \mathrm{~min}$, corresponding well with the time estimated by Øieroset et al. (1997) to achieve quasisteady conditions of $\sim 15 \mathrm{~min}$.

The one real difference between the observations presented here and prior expectations is that Øieroset et al. (1997) envisaged that a few-minute delay would occur between the cessation of open flux production at low latitudes due to the arrival of the TD, and the onset of high-latitude lobe reconnection and the appearance of lobe cells. During this initial interval the main observed effect would be a slow decay of the pre-existing twin-cell flow. In the radar data presented here, however, no significant interval of flow decay preceded the onset of sunward flows at $\sim 1120 \mathrm{UT}$, and no systematic variations in the magnetic data were recorded in the preceding interval either (Fig. 4). We thus conclude that sunward flows began in the dayside ionosphere within $\sim 2$ min of the appearance of the first effects of the TD, even allowing for reasonable propagation delays from outside the region of coverage. The implication appears to be that lobe reconnection starts more promptly following a northward turn of the IMF than envisaged by Øieroset et al. (1997), possibly due to the draped configuration of the magnetosheath field over the magnetopause. In addition to this, the continued presence of the low-latitude flow cells in the "after" condition was not included in the description provided by Øieroset et al. (1997), because there was no direct evidence for them in the optical data which they studied. The transition observed in the dusk sector flow in the data presented here is presumably related to the evolution in the form of these cells under the influence of the evolving lobe cell flow, and as a consequence of the changed IMF $B_{y}$ condition after the arrival of the TD.

Acknowledgements. We would like to thank Dr K.W. Ogilvie, NASA Goddard Space Flight Center, for providing Solar Wind Experiment data from the WIND spacecraft, and Dr T.J. Hughes for help with the CANOPUS data. The CANOPUS ground-based network is supported by the Canadian Space Agency. The IMAGE magnetometer data were collected as a German-Finnish-Norwegian-Polish project conducted by the Technical University of Braunschweig. DMSP data were provided under grant ATM 9501295. The CUTLASS-Finland radar is deployed and operated by the University of Leicester, and is jointly funded by the UK Particle Physics and Astronomy Research Council, the Finnish Meteorological Institute, and the Swedish Institute for Space Physics. The Goose Bay and Kapuskasing SuperDARN radars are supported by NSF Grant ATM 9502993 and NASA grant NAG 51099 respectively. The Saskatoon SuperDARN radar is supported by Collaborative Special Project Grant 119615. The operation of the SuperDARN radar in Stokkseyri, Iceland, is supported by the Institut National des Sciences de l'Univers (INSU). J.R.T. was supported by PPARC grant GR/J 88937.

Topical Editor D. Alcaydé thanks P. Stauning and another referee for their help in evaluating this paper.

\section{References}

Baker, K. B., and S. Wing, A new magnetic coordinate system for conjugate studies at high latitudes, J. Geophys. Res., 94, 91399143, 1990 .
Burch, J. L., P. H. Reiff, J. D. Menietti, R. A. Heelis, W. B. Hanson, S. D. Shawhan, E. G. Shelley, M. Sugiura, D. R. Weimer, and J. D. Winningham, IMF $B_{y}$-dependent plasma flow and Birkeland currents in the dayside magnetosphere 1., Dynamics Explorer observations, J. Geophys. Res., 90, 15771593, 1985.

Cowley, S. W. H., Magnetospheric asymmetries associated with the Y-component of the IMF, Planet. Space Sci., 29, 79-96, 1981.

Cowley, S. W. H., and M. Lockwood, Excitation and decay of solar wind-driven flows in the magnetosphere-ionosphere system, Ann. Geophysicae, 10, 103-115, 1992.

Cowley, S. W. H., and M. Lockwood, Incoherent scatter radar observations related to magnetospheric dynamics, Adv. Space Res., 20, (4/5)873-(4/5)882, 1997.

Cowley, S. W. H., J. P. Morelli, and M. Lockwood, Dependence of convective flows and particle precipitation in the high-latitude dayside ionosphere on the $\mathrm{X}$ and $\mathrm{Y}$ components of the interplanetary magnetic field, J. Geophys. Res., 96, 5557-5564, 1991.

Dungey, J. W., Interplanetary magnetic field and the auroral zones, Phys. Rev. Lett., 6, 47-48, 1961.

Dungey, J. W., The structure of the exosphere, or adventures in velocity space, in Geophysics: The Earth's Environment, Eds. C. DeWitt, J. Hieblot and A. LeBeau, pp. 503-550, Gordon and Breach, New York, 1963.

Etemadi, A., S. W. H. Cowley, M. Lockwood, B. J. I. Bromage, D. M. Willis, and H. Lühr, The dependence of high-latitude dayside ionospheric flows on the north-south component of the IMF: a high time resolution correlation analysis using EISCAT "Polar" and AMPTE-UKS and -IRM data, Planet. Space Sci., 36, 471498, 1988.

Freeman, M. P., C. J. Farrugia, S. W. H. Cowley, and A. Etemadi, The response of dayside ionospheric convection to the Ycomponent of the magnetosheath magnetic field: a case study, Planet. Space Sci., 38, 13-41, 1990.

Greenwald, R. A., K. B. Baker, R. A. Hutchins, and C. Hanuise, An HF phased array radar for studying small-scale structure in the high-latitude ionosphere, Radio Sci., 20, 63-79, 1985.

Greenwald, R. A., K. B. Baker, J. M. Ruohoniemi, J. R. Dudeney, M. Pinnock, N. Mattin, J. M. Leonard, and R. P. Lepping, Simultaneous conjugate observations of dynamic variations in high-latitude dayside convection due to changes in IMF $B_{y}, J$. Geophys. Res., 95, 8057-8072, 1990.

Greenwald R. A., et al., DARN/SuperDARN: a global view of high latitude convection, Space Sci. Rev., 71, 763-796, 1995a.

Greenwald, R. A., W. A. Bristow, G. J. Sofko, J.-C. Cerisier, and A. Szabo, Super Dual Auroral Radar Network radar imaging of dayside high-latitude convection under northward interplanetary magnetic field: toward resolving the distorted two-cell versus multicell controversy, J. Geophys. Res., 100, 1966119674, 1995b.

Hairston, M. R., and R. A. Heelis, Response time of the polar ionospheric convection pattern to changes in the north-south direction of the IMF, Geophys. Res. Lett., 22, 631-634, 1995.

Hanuise, C., C. Senior, J.-C. Villain, R. A. Greenwald, J. M. Ruohoniemi, and K. B. Baker, Instantaneous mapping of highlatitude convection with coherent HF radars, J. Geophys. Res., 98, 17387-17400, 1993.

Jørgensen, T. S., E. Friis-Christensen, and J. Wilhjelm, Interplanetary magnetic field direction and high-latitude ionospheric currents, J. Geophys. Res., 77, 1976-1980, 1972.

Lepping, R. P., et al., The WIND magnetic field investigation, Space. Sci. Rev., 71, 207-229, 1995

Lepping R. P., A. Szabo, M. Peredo, and J. T. Hoeksema, Largescale properties and solar connection of the heliospheric current and plasma sheets: WIND observations, Geophys. Res. Lett., 23, 1199-1202, 1996.

Lester, M., O. de la Beaujardière, J. C. Foster, M. P. Freeman, H. Lühr, J. M. Ruohoniemi, and W. Swider, The response of the large scale ionospheric convection pattern to changes in the 
IMF and substorms: results from the SUNDIAL 1987 campaign, Ann. Geophysicae, 11, 556-571, 1993.

Milan, S. E., M. Lester, S. W. H. Cowley, J. Moen, P. E. Sandholt, and C. J. Owen, Meridian-scanning photometer, coherent HF radar and magnetometer observations of the cusp: a case study, Ann. Geophysicae, submitted, 1998.

Němeček, Z., and J. Šafránková, The Earth's bow shock and magnetopause position as a result of the solar wind-magnetopause interaction, J. Atmos. Terr. Phys., 53, 1049-1054, 1991.

Newell, P. T., C.-I. Meng, D.G. Sibeck, and R. Lepping, Some lowaltitude cusp dependencies on the interplanetary magnetic field, J. Geophys. Res., 94, 8921-8927, 1989.

Nishida, A., Physics and chemistry in Space 9: geomagnetic diagnosis of the magnetosphere, Springer-Verlag, Berlin Heidelberg New York, 1978.

Ogilvie, K. W., et al., SWE - a comprehensive plasma instrument for the WIND spacecraft, Space Sci. Rev., 71, 55-77, 1995.

Øieroset, M., P. E. Sandholt, W. F. Denig and S. W. H. Cowley, Positive $B_{z}$ cusp aurora and high-latitude magnetopause reconnection, J. Geophys. Res., 102, 11349-11362, 1997.

Phan, T.-D., G. Paschmann, W. Baumjohann, and N. Sckopke, The magnetosheath region adjacent to the dayside magnetopause; AMPTE/IRM observations, J. Geophys. Res., 99, 121-141, 1994.

Reiff, P. H., and J. L. Burch, IMF $B_{\boldsymbol{y}}$-dependent plasma flow and Birkeland currents in the dayside magnetosphere: 2 A global model for the northward and southward IMF, J. Geophys. Res., 90, 1595-1609, 1985.

Rostoker, G., J. C. Samson, F. Creutzberg, T. J. Hughes, D. R. McDiarmid, A. G. MacNamara, A. Vallance Jones, D. D. Wallis, and L. L. Cogger, CANOPUS - a ground-based instrument array for remote sensing the high latitude ionosphere during the ISTP/GGS program, Space Sci. Rev., 71, 743760, 1995.

Russell, C. T., The configuration of the magnetosphere, in Critical problems of magnetospheric physics, Ed. E. R. Dyer, pp. 1-16, National Academy of Sciences, Washington, DC, 1972.

Shen, W.-W., and M. Dryer, Magnetohydrodynamic theory for the interaction of an interplanetary double-shock ensemble with the earth's bow shock, J. Geophys. Res., 77, 4627-4644, 1972.
Siscoe, G. L., and T. S. Huang, Polar cap inflation and deflation, $J$. Geophys. Res., 90, 543-547, 1985.

Spreiter, J. R., and S. S. Stahara, A new predictive model for determining solar wind-terrestrial planet interactions, J. Geophys. Res., 85, 6769-6777, 1980.

Spreiter, J. R., A. L. Summers, and A. Y. Alksne, Hydrodynamic flow around the magnetosphere, Planet. Space Sci., 14, 223-353, 1979.

Tamao, T., Unsteady interactions of solar wind disturbances with the magnetosphere, J. Geophys. Res., 80, 4230-4236, 1975.

Taylor, J. R., T. K. Yeoman, M. Lester, M. J. Buonsanto, J. L. Scali, J. M. Ruohoniemi, and J. D. Kelly, Ionospheric convection during the magnetic storm of 20-21 March 1990, Ann. Geophysicae, 12, 1174-1191, 1994.

Todd, H., S. W. H. Cowley, M. Lockwood, D. M. Willis, and H. Lühr, Response time of the high-latitude dayside ionosphere to sudden changes in the north-south component of the IMF, Planet. Space Sci., 36, 1415-1428, 1988.

Viljanen, A., and L. Häkkinen, IMAGE magnetometer network, in Satellite-ground based coordination sourcebook, ESA SP-1198, European Space Agency, Noordwijk, pp. 111-117, 1997.

Volkmer, P. M., and F. M. Neubauer, Statistical properties of fast magnetoacoustic shock waves in the solar wind between $0.3 \mathrm{AU}$ and 1 AU: Helios-1,2 observations, Ann. Geophysicae, 3, 1-12, 1985.

Wilken, B., C. K. Goertz, D. N. Baker, P. R. Higbie, and T. A. Fritz, The SSC on July 29, 1977 and its propagation within the magnetosphere, J. Geophys. Res., 87, 5901-5910, 1982.

Yeoman, T. K., and M. Lester, Characteristics of MHD waves associated with storm sudden commencements observed by SABRE and ground magnetometers, Planet. Space Sci., 38, 603-616, 1990.

Yeoman, T. K., M. Lester, S. W. H. Cowley, S. E. Milan, J. Moen, and P. E. Sandholt, Simultaneous observations of the cusp in optical, DMSP and HF radar data, Geophys. Res. Lett., 24, 2251-2254, 1997.

Zhuang, H. C., C. T. Russell, E. J. Smith, and J. T. Gosling, Threedimensional interaction of interplanetary shock waves with the bow shock and magnetopause: a comparison of theory with ISEE observations, J. Geophys. Res., 86, 5590-5600, 1981. 